\title{
Platelets, Constant and Cooperative Companions of Sessile and Disseminating Tumor Cells, Crucially Contribute to the Tumor Microenvironment
}

\section{OPEN ACCESS}

Edited by:

Ana Karina Oliveira, National Center for Research

in Energy and Materials, Brazi

Reviewed by:

Yi Yang,

University of North Carolina at Chapel Hill, United States

Ana Paula Campanelli,

University of São Paulo, Brazil

*Correspondence:

Johannes A. Eble

johannes.eble@uni-muenster.de

Specialty section

This article was submitted to

Molecular Medicine,

a section of the journal

Frontiers in Cell and Developmental

Biology

Received: 01 March 2021

Accepted: 29 March 2021

Published: 16 April 2021

Citation:

Obermann WMJ, Brockhaus K

and Eble JA (2021) Platelets,

Constant and Cooperative

Companions of Sessile

and Disseminating Tumor Cells,

Crucially Contribute to the Tumor

Microenvironment.

Front. Cell Dev. Biol. 9:674553.

doi: 10.3389/fcell.2021.674553

\section{Wolfgang M. J. Obermann, Katrin Brockhaus and Johannes A. Eble* \\ Institute of Physiological Chemistry and Pathobiochemistry, University of Münster, Münster, Germany}

Although platelets and the coagulation factors are components of the blood system, they become part of and contribute to the tumor microenvironment (TME) not only within a solid tumor mass, but also within a hematogenous micrometastasis on its way through the blood stream to the metastatic niche. The latter basically consists of blood-borne cancer cells which are in close association with platelets. At the site of the primary tumor, the blood components reach the TME via leaky blood vessels, whose permeability is increased by tumor-secreted growth factors, by incomplete angiogenic sprouts or by vasculogenic mimicry (VM) vessels. As a consequence, platelets reach the primary tumor via several cell adhesion molecules (CAMs). Moreover, clotting factor VII from the blood associates with tissue factor (TF) that is abundantly expressed on cancer cells. This extrinsic tenase complex turns on the coagulation cascade, which encompasses the activation of thrombin and conversion of soluble fibrinogen into insoluble fibrin. The presence of platelets and their release of growth factors, as well as fibrin deposition changes the TME of a solid tumor mass substantially, thereby promoting tumor progression. Disseminating cancer cells that circulate in the blood stream also recruit platelets, primarily by direct cell-cell interactions via different receptorcounterreceptor pairs and indirectly by fibrin, which bridges the two cell types via different integrin receptors. These tumor cell-platelet aggregates are hematogenous micrometastases, in which platelets and fibrin constitute a particular TME in favor of the cancer cells. Even at the distant site of settlement, the accompanying platelets help the tumor cell to attach and to grow into metastases. Understanding the close liaison of cancer cells with platelets and coagulation factors that change the TME during tumor progression and spreading will help to curb different steps of the metastatic cascade and may help to reduce tumor-induced thrombosis.

Keywords: platelets, tumor microenvironment, coagulation, thrombus formation, fibrin, tissue factor, CLEC-2, integrins 


\section{INTRODUCTION}

It may not be obvious to consider platelets and coagulation factors as components of the tumor microenvironment (TME), as they are blood components while the TME of a solid tumor mass consists of cancer cells, resident and infiltrating cells, and the dense network of extracellular matrix (ECM) (Iozzo and Sanderson, 2011; Theocharis et al., 2016; Henke et al., 2019; Martins Cavaco et al., 2020). Resident stroma cells may undergo a cancer cell-induced differentiation into cancer-associated fibroblasts (CAFs) (Pietras and Ostman, 2010; Kalluri, 2016; Wang et al., 2017), which remodel the ECM in a tumor-supportive manner (Eble and Niland, 2019). Also, infiltrating immune cells are influenced by tumor cells and thus attenuate their tumor-suppressive properties (Huber et al., 2020; Sadeghalvad et al., 2020; Yang et al., 2020). The noncellular ECM, mostly synthesized, secreted, and arranged by CAFs, consists of collagen-containing fibrils, water-resorbing proteoglycans and glycosaminoglycans and a plethora of other ECM-proteins (Eble and Niland, 2019; Niland and Eble, 2020). Together, they form the scaffold, which keeps the tissue in shape and provides a stiff collagenous capsule of desmoplastic tumors (Leight et al., 2017; Mohammadi and Sahai, 2018; Martins Cavaco et al., 2020). Moreover, the ECM scaffold tethers growth factors, forming the morphogenic stage for cell differentiation (Lodyga and Hinz, 2020; Wei et al., 2020). Also the presence of metabolic components, such as protons, lactate, reactive oxygen species (ROS), contribute to the typical environment of cancer cells in a solid tumor mass (Oudin and Weaver, 2016).

Primarily, the site of neoplasia within epithelia or stroma tissue is not connected directly to the blood. The tumor mass seems far away from the blood, the usual environment of platelets and coagulation factors. However, in at least two scenarios, cancer cells and the blood components come close to each other: either, when the hypoxic TME induces angiogenic ingrowth of sprouting capillaries into the tumor mass (De Palma et al., 2017; Klein, 2018; Zanotelli and Reinhart-King, 2018), or when cancer cells hematogenously disseminate from their prime tumor site to colonize distant organs (Erpenbeck and Schon, 2010; Schlesinger, 2018). In both cases, cancer cells come in close contact with the blood components. Consequentially, platelets and coagulation factors play a crucial role in tumor progression and metastasis (Menter et al., 2017; Burbury and MacManus, 2018; Mege et al., 2019).

The liaison between tumor cells and platelets is clinically relevant, as tumor-induced thromboembolism is the second leading cause of death in cancer patients (Gay and FeldingHabermann, 2011a; Connolly and Francis, 2013; Mege et al., 2019; Palacios-Acedo et al., 2019). This frequent complication of enhanced and inappropriate platelet activation and blood coagulation in cancer patients has been known for one and a half century, since the physician Armand Trousseau described this type of thrombophlebitis in 1865 (Trousseau, 1865), later generally named Trousseau syndrome (Han et al., 2014).

This review highlights the molecular interactions of platelets and the coagulation system with tumor cells, thereby showing that these blood components are constituents of the TME, even only temporarily, but with an important impact on tumor progression and hematogenous metastasis.

\section{PLATELETS, THE CELLULAR PLAYERS IN HEMOSTASIS}

Platelets are anuclear cells with a diameter of $2-5 \mu \mathrm{m}$ and a thickness of about $0.5 \mu \mathrm{m}$, which float in the blood stream at a density of 150,000-400,000 per $\mu \mathrm{l}$. After they pinch off from the large megakaryocytes in the bone marrow, these small cells spend their lifetime of around 5-7 days in the blood circulation, unless they detect a damage within the endothelium-lined blood vessel wall (Andrews and Berndt, 2004). They are also recruited to more severe tissue damages, where both the endothelial lining and the underlaying basement membrane are breached, and the adventitial stroma tissue around the blood vessel is injured. There, platelets attach and close the wound. Thus, they stop the blood leakage into the tissue and fulfill their hemostatic functions, for which they are predominantly known (Andrews and Berndt, 2004, 2008; Gale, 2011; Broos et al., 2012; Menter et al., 2017).

Attachment is mediated by several cell adhesion molecules (CAMs), which not only anchor the platelets to the wound area, but also trigger signals within the platelets, that activate them (Broos et al., 2012). Activation of platelets is accompanied by a remarkable shape change (Yeung et al., 2018). Quiescent platelets have a discoid shape, which upon activation changes into a stellate-like appearance with pronounced platelet spreading and formation of lamellipodia and numerous filipodia. These protrusions enable platelets to entangle with each other, to spread on an adhesive substrate, generally at the injury site of a wounded blood vessel, and to form the primary thrombus (Gale, 2011; Broos et al., 2012; Berndt et al., 2014). Another step of platelet activation is degranulation. Platelets contain different types of granules, among them $\alpha$-granules and dense granules, which upon platelet activation undergo exocytosis and release their contents (Gay and Felding-Habermann, 2011a). The former contain (i) ECM-proteins, such as von-Willebrand factor (vWF), fibrinogen, thrombospondin, (ii) coagulation factor $\mathrm{V}$ and VIII, the latter associated with vWF, (iii) growth factors, such as platelet-derived growth factor (PDGF), and (iv) membraneanchored CAMs, such as P-selectin, which thus becomes exposed on the platelet surface exclusively after platelet activation. Dense granules are rich in adenosine diphosphate (ADP), adenosine triphosphate (ATP), serotonin, and histamine. Whereas the release of the ECM proteins, especially $\mathrm{VWF}$, increases the adhesion of platelets (Grassle et al., 2014; Lancellotti et al., 2019), the purine nucleotides attract and activate additional platelets thereby increasing the size of the primary thrombus (Jamasbi et al., 2017; Yeung et al., 2018).

Platelet adhesion is crucial for thrombus formation (Andrews and Berndt, 2008; Broos et al., 2012; Jamasbi et al., 2017; Huang et al., 2019). Several CAMs enable platelets to attach firmly to an injured blood vessel wall, which is necessary to withstand the shear forces of the blood stream (Kunicki, 2001; Andrews and Berndt, 2008; Hansen et al., 2018). In addition to their mechanical functions, most of the CAMs also fulfill signaling 
functions, via which platelets perceive the environmental cues of adhesion (Yeung et al., 2018). Thus, adhesion triggers platelet activation, which in turn reinforces the binding activity of platelet CAMs to their ECM ligands. Amongst the plethora of platelet CAMs, we will focus on the vWF-binding GPIb-complex, on the collagen-binding receptors, glycoprotein (GP) VI and integrin $\alpha 2 \beta 1$, and on the fibrin receptor, integrin $\alpha \operatorname{IIb} \beta 3$ (Kunicki, 2001; Gay and Felding-Habermann, 2011a; Jamasbi et al., 2017; Martins Lima et al., 2019).

The vWF-receptor consists of four transmembrane protein chains, GPIb $\alpha$, GPIb $\beta$, GPIX, GPV, which assemble into the GPIb-complex in a 2:2:2:1 stochiometry within the platelet membrane (Kunicki, 2001; Andrews et al., 2003; Quach and $\mathrm{Li}, 2020)$. The GPIb $\alpha$ chain harbors the binding site for vWF (Lof et al., 2018; Lancellotti et al., 2019). vWF is a large ECM molecule consisting of several modules, which are assigned to four different types of domains; A, B, C, and D (Lancellotti et al., 2019). It is stored in the Weibel-Palade bodies of endothelial cells and after exocytosis multimerizes into a scaffold within the subendothelial basement membrane. In solution, it takes on a globular structure, in which also domain A1 with its GPIbbinding site is in a cryptic state (Huck et al., 2014; Lof et al., 2018). Upon association with other immobilized ECM proteins, e.g., with collagens via its A3 domain, and under hydrodynamic shear forces, vWF unwinds into an extended shape, which makes its A1 domain accessible to the platelet GPIb complex (Huck et al., 2014; Hansen et al., 2018). Thus, vWF bridges platelet attachment to collagen even under high blood flow rates, such as observed within the arterial branch of the circulatory system (Kulkarni et al., 2000; Hansen et al., 2018). Moreover, the GPIbcomplex-mediated attachment of platelets to vWF and collagen under high shear forces results in stretching of the GPIb-chain and thus triggers an activating signal which is further transduced via the phosphoprotein-binding adaptor protein 14-3-3 within the platelet (Chen et al., 2018; Scharf, 2018b; Quach and Li, 2020).

The direct interaction of platelets with collagens is mediated via two distinct receptors, GPVI and $\alpha 2 \beta 1$ integrin (Nuyttens et al., 2011). Apparently, GPVI is physically associated in the platelet membrane with the GPIb complex (Arthur et al., 2005). GPVI is a type I transmembrane protein consisting of an extracellular tandem domain of two immunoglobulin C2 (Ig C2)-like modules, a glycosylated mucin-like stalk domain, a transmembrane and short cytoplasmic domains (Nieswandt and Watson, 2003). The Ig C2-like domains recognize bundles of collagen molecules, which contain the posttranslationally modified hydroxyproline residues that are essential for binding (Knight et al., 1999). Binding to collagen depends on the N-linked glycoconjugates of GPVI (Kunicki et al., 2005). High affinity binding of collagen also requires dimerization of GPVI receptors, which then signals via the associated Fc-receptor $\gamma$-chain $(\mathrm{FcR} \gamma)$ (Miura et al., 2002; Nieswandt and Watson, 2003). Deficiency of GPVI (Kato et al., 2003) or its inhibition by antibodies or pharmaceuticals (Nieswandt et al., 2001; Martins Lima et al., 2019) affect thrombus formation, although hemostasis, measured as bleeding time, is affected only mildly. In contrast to GPVI, the other collagen receptor on platelets, $\alpha 2 \beta 1$ integrin, belongs to the large family of integrins, consisting of two non-covalently associated subunits, $\alpha$ and $\beta$ (Madamanchi et al., 2014; Zheng and Leftheris, 2020). The two integrin chains jointly form a globular head domain, which harbors the ligand binding site (Arnaout et al., 2005). All collagen-binding integrins contain an additional A-domain, which sits on top of the $\alpha$-subunit propeller domain and is responsible for collagen binding (Emsley et al., 2000; Eble, 2005). The collagen ligands do not necessarily need to bear hydroxyproline residues (Perret et al., 2003; Niland et al., 2011), but the triple helical array of a specific collagenous integrin binding motif is indispensably required (Kühn and Eble, 1994; Hamaia and Farndale, 2014). Integrins undergo substantial changes in their conformation, which is influenced by ligand occupancy and, in turn, influences ligand binding (Arnaout et al., 2005; Luo et al., 2007; Hanein and Volkmann, 2018). Moreover, upon collagen binding, $\alpha 2 \beta 1$ integrins cluster on the platelet surface, likely mirroring the supramolecular array of integrin binding sites on collagen fibrils (Lima et al., 2018). This is similar to the ligand-induced clustering of GPVI and other CAMs on platelets (Ozaki et al., 2013; Poulter et al., 2017), which triggers a signaling cascade and thus induces platelet activation and aggregation (Humphries et al., 2019). The redundancy of the collagen receptors, GPVI and $\alpha 2 \beta 1$ integrin, on platelets has prompted several discourses and models, as the individual deletion of either of them did not entirely abolish collageninduced platelet activation (He et al., 2003; Marjoram et al., 2014). Their interplay in collagen-induced platelet activation is still not entirely clear. Apparently, the two receptors influence each other in their signaling potential, as activation of GPVI seems to be regulated by $\alpha 2 \beta 1$ integrin (Atkinson et al., 2003), and vice versa (Inoue et al., 2003). The signals of both receptors convene into an integrating network (Lima et al., 2018; Izquierdo et al., 2020). Yet, another model postulates that GPVI is more involved in signal transduction, whereas $\alpha 2 \beta 1$ integrin firmly attaches the platelet mechanically to the collagen thereby allowing the forming thrombus to withstand the shear forces of the blood (Kunicki, 2001; Jarvis et al., 2004; Pugh et al., 2010).

The most numerous adhesion receptor with 50,000-100,000 molecules on the surface of a quiescent platelet and with many more molecules exposed upon platelet activation is the fibrin receptor, integrin $\alpha \operatorname{IIb} \beta 3$ (Coller, 2015; Huang et al., 2019). Not only the numbers of surface-exposed integrin $\alpha \operatorname{IIb} \beta 3$ molecules, but also the activation state of these fibrin receptors is essential for effective platelet adhesion to fibrin. On quiescent platelets, integrin $\alpha \operatorname{IIb} \beta 3$ is in its inactive conformation, in which the globular integrin head domain bent back toward the platelet cell membrane. Only upon platelet activation, such as by the precedent binding of $\mathrm{vWF}$ and collagen to their respective receptors, cytoplasmic adaptor molecules, particularly talin and kindlin, bind to the $\alpha \mathrm{IIb} \beta 3$ integrin (Moser et al., 2008; KasirerFriede et al., 2014). Via this so-called in-side out signaling, the unclasping of the cytoplasmic domains and membraneproximal stalk domains of both integrin subunits as well as a conformational extension of the integrin ectodomains is induced. This goes along with an enhancement of binding affinity to the fibrin ligand (Arnaout et al., 2005; Luo et al., 2007; Huang et al., 2019; Humphries et al., 2019) and integrin clustering (Li et al., 2017), which eventually enables platelets to firmly attach to fibrin 
scaffolds and to exert contractile forces onto it (White, 2000; Haling et al., 2011).

\section{THE PROTHROMBOTIC MICROENVIRONMENT OF SOLID TUMORS}

Under healthy conditions, hemostasis aims to seal any damage of the otherwise leakproof circulatory system, to stop bleeding and to initiate tissue regeneration by providing a provisional ECM network of fibrin. These tasks are accomplished by the interdependent network of platelets, blood coagulation factors, and the blood vessel wall (Gale, 2011; Broos et al., 2012; Berndt et al., 2014).

The final product of the coagulation pathway is fibrin (Jennewein et al., 2011; Swieringa et al., 2018; Kwaan and Lindholm, 2019). Coagulation comprises a complex network of serine proteinases, which float in the blood plasma in an inactive zymogenic form (Dahlbäck, 2000; Gale, 2011). Intrinsic hemostasis is triggered intravascularly by negatively charged surfaces and kallikrein, at injured sites of the vessel wall, where endothelial cells detach and leave a desnuded basement membrane (Figure 1). This triggers a cascade of partial proteolysis steps, by which clotting factors XII, XI, and IX activate each other sequentially (Gale, 2011). Platelets also attach to the denuded vessel wall, are activated and thus take on a dendritic cell shape. Activated factor IX associates with activated factor VIII in a $\mathrm{Ca}^{2+}$ ion-dependent manner on the surface of these activated platelets, a process which is supported by the enrichment of phosphatidylserine residues in the outer membrane leaflet (de Witt et al., 2014; Swieringa et al., 2018). This intrinsic tenase complex is named according to its substrate, clotting factor X ( $\mathrm{X}$ being the Roman numeral for 10). It proteolytically cleaves factor $X$, which together with activated factor $\mathrm{V}$ forms yet another coagulant complex on the platelet surface, the prothrombinase complex, resulting in active thrombin (factor II) (Wojtukiewicz et al., 2016; Reddel et al., 2019). In addition to fibrinogen conversion, thrombin is able to activate several upstream clotting factors, thereby perpetuating and amplifying coagulation. Moreover, thrombin elicits intracellular signals by activating proteaseactivated receptors (PARs), thereby reinforcing platelet activation (Wojtukiewicz et al., 2015). In the context of hemostasis, it converts soluble fibrinogen monomers into insoluble fibrin molecules. They aggregate into highly ordered supramolecular bundles that form rope-like structures and networks, that stabilize the platelet aggregates and allow the platelets to contract the resulting thrombus (Gale, 2011). Factor XIII, a transglutaminase, secreted from the platelets, covalently crosslinks the fibrin molecules, thereby strengthening thrombus stability. Several control mechanisms are implemented into this network of coagulation to avoid spatially or temporarily inappropriate or overshooting hemostasis, which would cause vascular occlusion, thrombosis and consequentially ischemia (Connolly and Francis, 2013). Among them, thrombin triggers also the anticoagulant circuit of protein $\mathrm{C}$ activation to confine the coagulation cascade locally and temporally (Dahlbäck, 2000; Gale, 2011).

The tight lining of endothelial cells prevents platelets and fibrinogen from getting in contact with extravascular protagonists that trigger activation of platelets and of coagulation factors (Nagy et al., 2012; Benazzi et al., 2014; Fitzgerald et al., 2018; Klein, 2018). During vessel damage and tissue injury, platelets and fibrinogen from the blood meet these prothrombotic and coagulant agents, thereby physiologically leading to hemostasis and to the generation of fibrin-scaffolded granulation tissue, which in normal tissue would be the first step in wound healing and tissue regeneration (Menter et al., 2017). However, where do platelets meet cancer cells that grow in a solid mass within epithelial or stromal tissue? How do platelets become part of the TME? The answers lay in the high permeability of blood vessels in the vicinity of a tumor mass (Nagy et al., 2012). This leakiness allows the intravascular platelets and fibrinogen to access the extravascular space, where platelets become activated and fibrinogen is converted to fibrin by coagulation (Figure 2). Depending on the type of tumor vessel, there are different ways, how tumor vessels lose their gatekeeper functions and allow extravasation of platelets and coagulation factors (Figure 2; Chouaib et al., 2010; Klein, 2018). First, the tumor mass approaches preexisting vessels due to its volume-demanding growth or by vessel co-option (Kuczynski et al., 2019; Niland and Eble, 2019). Vascular endothelial growth factor (VEGF), especially its isoform VEGF-A, and likely other chemokines from the TME increase the permeability of normal blood vessels and activate endothelial cells (Apte et al., 2019). This may result in increased leukocyte extravasion. Moreover, activation of endothelial cells is accompanied by the loss of antithrombotic surface molecules, such as thrombomodulin and heparin sulfate, from the endothelial cell surface (Klein, 2018). This increases the propensity of intravascular coagulation and thrombosis. Second, VEGF, produced by the cells of the tumor mass in response to the hypoxic TME, also stimulates angiogenesis. However, the ingrowing blood vessels are tortuous, variably calibered, and chaotically organized with a patchy and discontinuous lining of endothelial cells, while the underlying basement membrane is not fully established and defective, and the stabilizing mural cells, such as pericytes, are missing (Benazzi et al., 2014; Zanotelli and Reinhart-King, 2018). Thus, the irregular angiogenic vessels become another route for blood components to leak into the tumor mass (Figure 2). The blood flow in these vessels is irregular and likely turbulent, which also increases endothelium activation and leakiness. Vasculogenic mimicry (VM) vessels are a third option for extravasation of blood components into tumor tissue. Although their existence has been controversially discussed for the last two decades, VM vessels occur in a variety of solid tumors with a bad prognosis for the patient (Andonegui-Elguera et al., 2020; Wechman et al., 2020; Wei et al., 2021). These vessels are hardly or not at all lined by endothelial cells, but possess a sleeve of ECM glycoproteins. The latter are responsible for their detection with periodic acid fuchsin staining (PAS) reagent in histological sections. Moreover, in an attempt to confine the lumen of VM vessels, tumor cells align to shape a tube-like conduit. There, tumor cells are in contact with the 


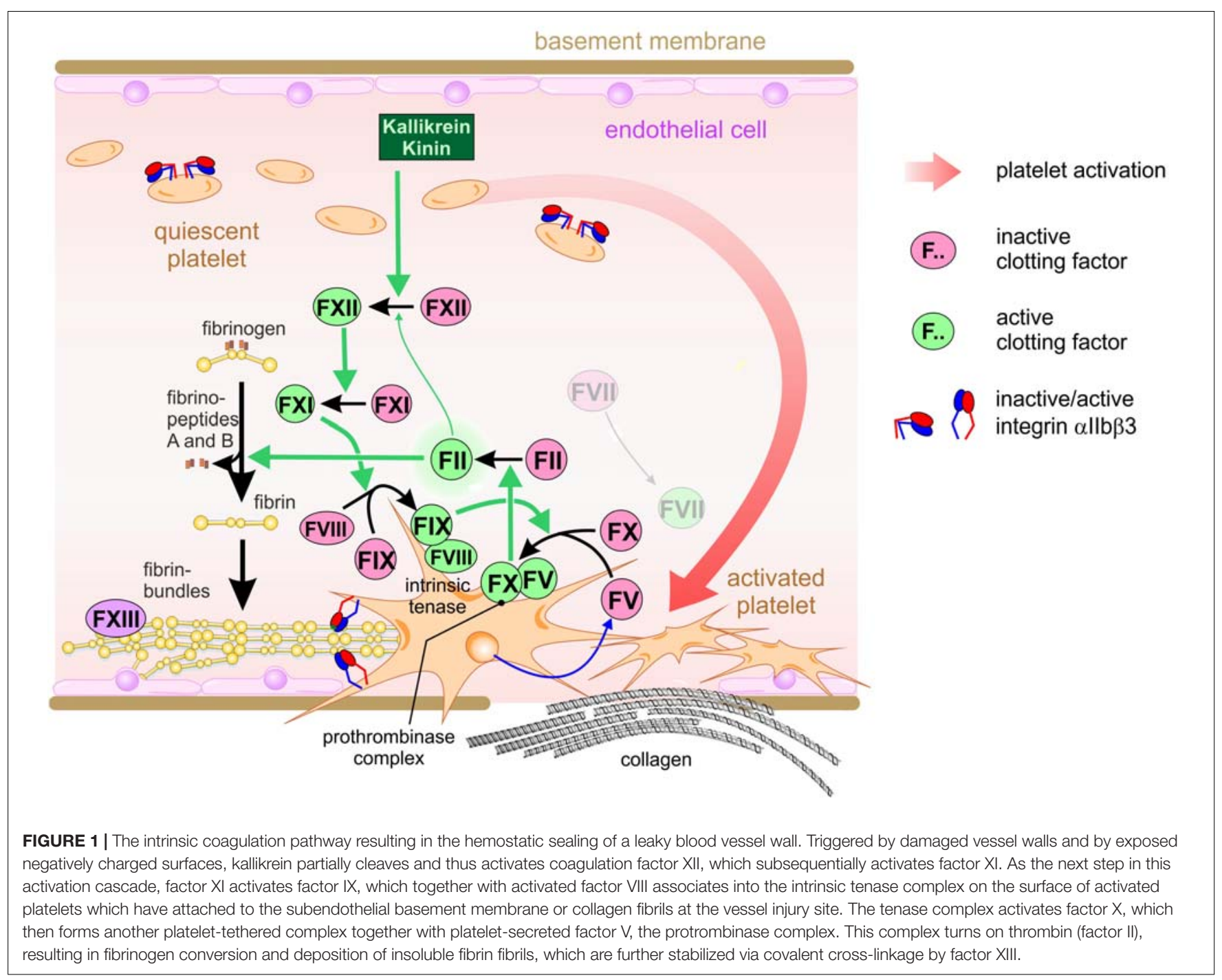

blood flow and, due to their discontinuous cell-cell contacts, give another route of extravasation of blood components. Along these three routes, blood components reach the tumor mass and contribute with their high colloid-osmotic pressure to the characteristically elevated interstitial pressure within the TME. The rigidity and tension of the ECM adds to this high interstitial pressure typical of the TME (Mohammadi and Sahai, 2018; Eble and Niland, 2019).

The subendothelial basement membrane and the underlying three-dimensional ECM scaffold significantly contributes to the TME (Eble and Niland, 2019; Mongiat et al., 2019). In leaky blood vessels, it gives way for platelets and coagulation factors to reach the interstitial ECM scaffold of the tumor mass and the cancer cells (Acerbi et al., 2015; Naba et al., 2016, 2017). Within the TME, the coagulation cascade preferentially runs along the extrinsic pathway. In contrast to intrinsic hemostasis, it is alternatively triggered by tissue factor (TF) (factor III, thromboplastin, CD142), which is expressed on adventitial stroma cells and is abundant on tumor cells. It recruits factor VII, which leaks into the TME and, upon proteolytic activation, predominantly cleaves factor X, but also factor XI. Therefore, this complex on tumor cells is called the extrinsic tenase complex (Repetto and De Re, 2017; Chowdary, 2020). Activated factor X and plateletreleased factor $\mathrm{V}$ form the prothrombinase complex on the platelet surface in a $\mathrm{Ca}^{2+}$ ion-dependent manner. This eventually activates thrombin (factor II), the central serine protease of coagulation (Figure 2).

Through the leaky tumor vessel, also platelets reach the tumor site in three subsequent steps: tethering, adhesion, and activation of platelets (Kunicki, 2001; Wong, 2013; Hansen et al., 2018; Scharf, 2018a). Platelets tether to subendothelial vWF, which is synthesized and secreted by endothelial cells. The shear forces of the turbulent blood flow in the tortuous and leaky tumor vessels change the conformation of vWF and enable its recognition by the GPIb-complex (Huck et al., 2014). This prepares the adhesion and activation steps of platelets, as tethering provides a sufficiently long period for other adhesion receptors to bind to additional ECM proteins. Then, due to their cytoskeleton rearrangement, platelets also actively migrate along the ECM into the TME (Wong, 2013). 


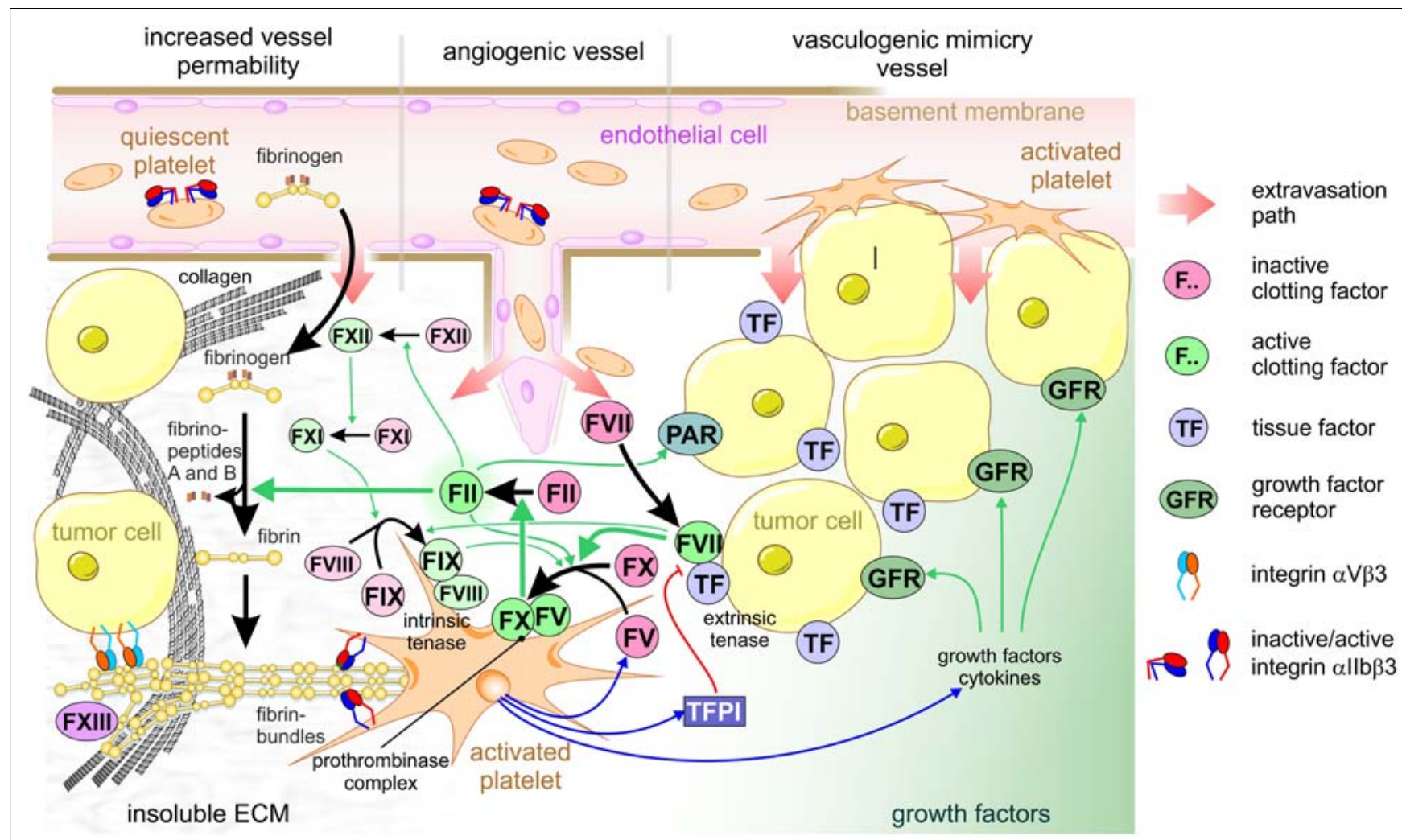

FIGURE 2 | Platelets are crucial for tumor cell-induced coagulation and contribute to the TME of solid tumors. Increased vessel permeability in the vicinity of a tumor tumor-induced angiogenic sprouting or vasculogenic mimicry vessels are three ways that allow extravasation of platelets and clotting factors from the blood stream into the interstitial stroma of tumor tissue. After the platelets recognize VWF of the subendothelial basement membrane, or collagen of the desmoplastic TME, platelets become activated, thereby take a dendritic shape, expose phosphatidylserine on the outer leaflet of cell membrane, degranulate, and activate the adhesion receptors, especially $\alpha$ llb $\beta 3$ integrin. After leaking from the blood vessel, clotting factor VII immediately is activated and associates with tissue factor, which is abundant on most tumor cells, thereby forming the extrinsic tenase complex. This activates factor X and XI, the former of which forms the prothrombinase complex, together with platelet-secreted factor $\mathrm{V}$, on the surface of activated platelets exposing phosphatidylserine. This activates thrombin (factor II). In addition to this main activation path, thrombin activation is perpetuated by integrating the intrinsic coagulation pathway: thrombin $>$ factor XII $>$ factor XI > intrinsic tenase complex (factor IX:FVIII) > factor $X>$ thrombin. Also, PARs are activated by thrombin on tumor cells, additionally promoting tumor progression. Activated thrombin converts soluble fibrinogen from the blood plasma to insoluble fibrin molecules that aggregate into highly ordered fibrin bundles. They change the composition of the TME substantially and allow further platelets to adhere. Activated platelets secrete not only factor V and factor VIII, but also tissue factor pathway inhibitor (TFPI), thereby feeding back on the extrinsic tenase complex, as well as growth factors. Relevant growth factor receptors, e.g., for PDGF and TGF $\beta$, provide proliferative signals to tumor cells.

Cancer cells and their neighboring stroma cells change the composition and physical properties of the ECM in the tumor mass remarkably (Eble and Niland, 2019; Henke et al., 2019). Distinct ECM proteins are abundantly deposited in the TME, such as collagen fibrils, fibronectin variants EDA and EDB, and tenascin-W (Acerbi et al., 2015; Naba et al., 2016, 2017; Eble and Niland, 2019; Niland and Eble, 2020). They are deposited in gradients within the TME, with high concentrations of collagens and fibronectin in the periphery of the tumor mass, especially of desmoplastic tumors (Oudin and Weaver, 2016; Wang et al., 2016; Eble and Niland, 2019). Therefore, approaching the tumor from the leaky vasculature, platelets first experience and attach to collagen, either via vWF, which via its A3-domain decorates collagen, or directly via collagen receptors. Collagen belongs to the strongest activators of platelets. Activated platelets further migrate into the tumor mass, a process which is likely reinforced by the distribution of ECM proteins and by other gradients within the TME, such as mechanical stiffness and tension, or of metabolites, acidic $\mathrm{pH}$ and oxygen tension (Oudin and Weaver, 2016). Thus, platelets enter the TME and become a part of it.

Shortly after their discovery in 2004, neutrophil extracellular traps (NETs) were pinpointed as another way of platelet extravasation and infiltration into the TME (Cedervall et al., 2018; Masucci et al., 2020). Upon activation and arrest at a leaky tumor vessel, neutrophil granulocytes may undergo NETosis, a suicidal process, which results in the production of ROS and release of decondensed nuclear and mitochondrial DNA into the extracellular space. Histones are modified and released from the denuded chromosomal DNA leaving behind a network of nucleic acid, originally meant to entrap pathogens (Masucci et al., 2020). However, these highly negatively charged nucleic acids form the surface, on which clotting factor XII is activitated, and vWF-bound factor VIII is enriched. Activated factor XII initiates the intrinsic pathway of coagulation, also at the sites of leaky tumor vessels (Campello et al., 2018). Moreover, this nucleic acid 
network also entraps platelets and allows them to extravasate at these TME-near vessel sites (Erpenbeck and Schon, 2017; Cedervall et al., 2018). Although not entirely clear today, NETmediated platelet entrapment is an alternative route of platelet recruitment to the TME.

\section{COOPERATION OF TUMOR CELLS AND PLATELETS WITHIN THE TME OF A SOLID TUMOR MASS}

Once in the physical vicinity of the tumor cells, platelets contribute to the TME in several ways (Gay and FeldingHabermann, 2011a; Menter et al., 2017). Activated platelets release clotting factors, V and VIII, which reinforce the coagulation cascade (Swieringa et al., 2018). In particular, by secreting factor $\mathrm{V}$, platelets complement the activity of the extrinsic tenase complex on the cancer cells, as both activated factors $\mathrm{V}$ and $\mathrm{X}$ form the prothrombinase complex on platelets (Camire, 2016). By flipping phosphatidylserine to their outer leaflet of the cell membrane, platelets form the platform for thrombin generation. Thrombin takes multiple roles within the TME by activating other tumor secreted proteases, by activating PARs on both platelets and cancer cells (Wojtukiewicz et al., 2015), and by remodeling the ECM scaffold and turning it to a fibrin-rich matrix (Repetto and De Re, 2017; Kwaan and Lindholm, 2019). Moreover, platelets store multiple growth factors, such as PDFG, VEGF, and transforming growth factor$\beta$ (TGF $\beta$ ), as well as several cytokines (Gay and FeldingHabermann, 2011a; Swieringa et al., 2018; Bikfalvi and Billottet, 2020). This cocktail of signaling molecules is secreted from activated platelets into the TME. VEGF supports angiogenesis of endothelial cells (Sabrkhany et al., 2011; De Palma et al., 2017; Apte et al., 2019). Certain platelet-derived cytokines suppress immune cells (Palacios-Acedo et al., 2019; Bikfalvi and Billottet, 2020). PDGF and TGF $\beta$ are strong stimulators for fibroblasts to differentiate into cancer-associated fibroblasts (CAFs) (Ostman, 2017; Lodyga and Hinz, 2020). CAFs convert the TME into a cancer cell-supportive environment by remodeling the ECM, by exerting mechanical forces and interstitial tension, and supporting tumor cell invasion (Kalluri, 2016; Eble and Niland, 2019; Pakshir et al., 2020). Another way of platelet-tumor cell-communications are microvesicles, which are secreted by platelets and are taken up by tumor cells in the TME (Goubran et al., 2015; Vajen et al., 2015).

A special cooperativity between platelets and tumor cells becomes evident in the formation of the extrinsic tenase complex on tumor cells. It contains tissue factor (TF), which is abundantly expressed on several tumor cells (Han et al., 2014; Versteeg, 2015; Grover and Mackman, 2018; Unruh and Horbinski, 2020). Moreover, its expression is upregulated in many tumor entities (Han et al., 2014 and references therein) and correlates with the malignancy grade of the tumors (Callander et al., 1992; Shoji et al., 1998; Liu et al., 2011; Zhang et al., 2020). Also, CAFs are a rich source of tissue factor and also form the extrinsic tenase complex, together with the factor VII that diffuses into the TME from the leaky blood vessels (Liu et al., 2011; Zhang et al., 2020).
Although it is unclear whether this prometastatic effect of TFFVII complex on tumor cells is caused by its proteolytic activity or its signaling function, practically, TF-inhibitory antibodies or FVII-deficiency reduce metastasis in murine breast cancer models (Versteeg, 2015; Rondon et al., 2019). Conspicuously, but not entirely understood is the regulatory interplay of tissue factor pathway inhibitor (TFPI), a Kunitz type domains-containing inhibitor of the tissue factor:factor VII-complex, which is secreted by activated platelets (Dahlback, 2017; Chowdary, 2020).

Two isoforms of tissue factor are generated by alternative splicing, a full length variant (flTF) and an alternatively spliced variant (asTF) (Unruh and Horbinski, 2020). They share the same $\mathrm{N}$-terminal ectodomain, which encompasses two fibronectin type III-domains, each with an intradomain disulfide bridge. Whereas flTF is anchored in the cell membrane via a single span transmembrane domain, the asTF only peripherally tethers to the cell membrane via five positively charged amino acid residues at the shortened C-terminus. Three $\mathrm{N}$-glycoconjugates may influence the association affinity for activated factor VII (Stone et al., 1995). The cytoplasmic domain of flTF may be phosphorylated and palmitoylated (Unruh and Horbinski, 2020). In addition to its coagulant function, the extrinsic tenase complex on cancer cells may also cleave ephrin receptors, ephB2 and ephA2 (Kania and Klein, 2016), or PAR2 (Wojtukiewicz et al., 2015). For instance, the latter initiates a signaling process of increased protein kinase $\mathrm{C}$ (PKC) activity and enhanced intracellular $\mathrm{Ca}^{2+}$ levels within the cancer cells (Unruh and Horbinski, 2020). Both flTF and asTF can also associate with distinct $\beta 1$ integrins, thereby inducing a conformational change and consequential increase of ligand binding activity and cell migration (Versteeg, 2015).

Of remarkable impact on ECM remodeling within the TME is the ability of the extrinsic tenase complex to trigger the coagulative conversion of fibrinogen into fibrin. This is not restricted to the immediate surroundings of the cancer cells, as cancer cells intensely secrete microparticles which contain flTF and phosphatidylserine. These microparticles are abundantly found in the blood of cancer patients. Due to their strong procoagulant potential, their abundance correlates with the risk of venous thromboembolism (Tesselaar et al., 2009; OwensIII, and Mackman, 2011) and may be a determinant in preparing premetastatic niches (Gkolfinopoulos et al., 2020).

At the primary tumor site, fibrin can be considered as a joint product of platelets and tumor cells, which changes the biochemical and biophysical composition of the TME (Eble and Niland, 2019). The fibrin network resembles the fibrinrich ECM of granulation tissue during wound repair. Via cell adhesion receptors, it feeds back on both platelets and cancer cells (Kwaan and Lindholm, 2019). Whereas platelets attach to fibrin via their most numerous receptor, integrin $\alpha \operatorname{IIb} \beta 3$, tumor cells recognize fibrin via $\alpha \mathrm{V} \beta 3$ integrin (Katagiri et al., 1995). The binding sites for both integrin receptors are different from each other and located at different sites within the $50 \mathrm{~nm}$ long fibrin molecule, allowing both receptors to bind to the same molecule without steric competition (Springer et al., 2008). Especially for platelets, the interaction with fibrinogen and fibrin is a complex and regulated process, as both platelet and fibrinogen 
are blood plasma components without interacting with each other under normal conditions. Quiescent platelets usually bear $\alpha \operatorname{IIb} \beta 3$ integrin in an inactive, bent conformation (Xiao et al., 2004). It does not bind to fibrinogen nor to cleaved fibrin molecules in solution (Vickers, 1998). Instead, fibrin must form highly ordered fibrils and networks or must be immobilized to surfaces to allow effective binding of $\alpha \operatorname{IIb} \beta 3$ integrin and platelet adhesion (Podolnikova et al., 2010). This requirement is fulfilled only after coagulation within the TME. Therefore, network formation and deposition of fibrin changes the adhesive properties of the TME for both platelets and cells. It enables $\alpha \operatorname{IIb} \beta 3$ integrin to be conformationally activated (Xiao et al., 2004; Podolnikova et al., 2009; Durrant et al., 2017). Like other ECM receptors, fibrin-bound $\alpha \operatorname{IIb} \beta 3$ integrin molecules likely cluster, in line with the pattern of integrin binding sites within the fibrin network (Ozaki et al., 2013; Martins Lima et al., 2019). Via outside-in signaling, they convey the adhesive signal into the platelet by recruiting cytoskeletal, adaptor, and kinase proteins, such as Src and focal adhesion kinase (FAK), to the cellular attachment site (Coller, 2015; Durrant et al., 2017; Huang et al., 2019). Platelets, especially those that leak out of the blood stream after the first thrombotic events are activated and reinforce the thrombotic and coagulant TME. Such adhesive clues of the fibrinenriched and remodeled ECM, together with the platelet-secreted growth factors, cytokines, and microvesicles decisively contribute to the TME and influence the TME-embedded cells, such as cancer cells, CAFs, immune cells and endothelial cells (Kalluri, 2016; Eble and Niland, 2019).

\section{BLOOD-BORNE TUMOR CELLS ARE SHELTERED AND SUPPORTED BY ASSOCIATING PLATELETS}

The physical interaction of platelets with tumor cells is not only relevant in the TME of solid tumors, but also crucial in the formation of blood-borne tumor cell-platelet aggregates (TCPAs) and hematogenous metastasis. Immediately after entering the bloodstream, tumor cells are coated with platelets on their surface. This cloak protects them from the shear stress, that they experience from the blood flow (Egan et al., 2014), and prevents them from being eliminated by the immune system (Palumbo et al., 2007; Gay and Felding-Habermann, 2011b). The formation of TCPAs is mediated by receptors on platelets that bind to their counterreceptors on tumor cells and by the establishment of fibrin bridges between the two cell types (Erpenbeck and Schon, 2010; Schlesinger, 2018). In this process, several interactions are responsible for the firm cohesion of platelets to tumor cells, such as the binding between (i) C-type lectin-like receptor 2 ( Clec-2) on platelets with podoplanin on tumor cells, (ii) P-selectin on activated platelets, and Sialyl-Lewis ${ }^{\mathrm{x}}$-conjugates on tumor cells, and (iii) the integrins $\alpha \operatorname{IIb} \beta 3$ on platelets and $\alpha \mathrm{V} \beta 3$ on tumor cells, which both bind to a fibrin bridge. TCPA formation is a multistep cascade initiated by $\mathrm{Clec}-2$ based platelet activation followed by fibrinogen conversion and fibrin bridging (Figure 3 ).

Clec-2 is an N-glycosylated type II membrane protein with a short cytoplasmic tail containing a hemi-immunoreceptor tyrosine-based activation motif (hemITAM) and a C-type lectinlike ectodomain (Nagae et al., 2014). It is exclusively expressed on the platelet membrane. Its counter piece is podoplanin, also known as aggrus, which appears in several tissues and is overexpressed on certain types of cancer cells (Suzuki-Inoue, 2019). Podoplanin is a type I membrane protein containing a short cytoplasmic tail which anchors the receptor to the actin cytoskeleton (Quintanilla et al., 2019) and an extracellular part harboring in tandem three copies of a platelet aggregation (PLAG) stimulating motif (Nagae et al., 2014). The third PLAG motif has an O-linked disialyl sugar moiety attached (Kaneko et al., 2007). Sialyation together with the acidic amino acids glutamate and aspartate in podoplanin's PLAG3 motif is essential for electrostatic contact with three arginine residues in $\mathrm{Clec}$ 2 and for stimulation of platelet aggregation, as revealed by structural analysis of the Clec-2-podoplanin protein complex (Nagae et al., 2014). Interaction with its agonist podoplanin results in translocation of Clec-2 into lipid rafts (Pollitt et al., 2010), mixtures of sphingolipids, cholesterol, and proteins that form membrane microdomains (Simons and Gerl, 2010). The dense packing in rafts mediates clustering of $\mathrm{Clec}-2$ receptors (Ozaki et al., 2013). The multimerization of Clec- 2 increases the affinity for podoplanin and in turn causes podoplanin clustering, resulting in a strong interaction between platelets and tumor cells (Pollitt et al., 2014).

Upon podoplanin-dependent Clec-2 clustering in lipid rafts, platelet activation is initiated by Clec- 2 signaling through its hemITAM sequence (Suzuki-Inoue, 2019). The hemITAM segment consists of the tyrosine phosphorylation motif YXXL adjacent to an upstream triple of acidic amino acids (Hughes et al., 2013). Phosphorylation of the hemITAM YXXL is catalyzed by a collaboration between Syk tyrosine kinase and a Src family tyrosine kinase (Spalton et al., 2009; Severin et al., 2011; Pollitt et al., 2014). This enables Syk to avidly bind with its pair of Src homology (SH2) domains to the phosphorylated hemITAM sequences of two Clec-2 molecules that form a dimer (Watson et al., 2009). Thereby, the catalytic activity of the tyrosine kinase Syk is further boosted (Suzuki-Inoue, 2019). Eventually, Syk starts a downstream signaling cascade by phosphorylation of the adaptor proteins, LAT (linker for activation of T cells) and SLP-76 (Src homology 2 domain-containing leukocyte protein of $76 \mathrm{kDa}$ ), leading to activation of Btk (Bruton tyrosine kinase) and PLC $\gamma 2$ (phospholipase C $\gamma 2$ ). Finally, cleavage of phosphatidylinositol-4,5-biphosphate (PIP2) by PLC $\gamma 2$ generates the second messenger molecules IP3 (inositol 1,4,5-triphosphate) and DAG (diacylglycerol), that increase intracellular $\mathrm{Ca}^{2+}$ levels and activation of PKC (protein kinase C), resulting in platelet activation (Pollitt et al., 2010; Suzuki-Inoue, 2019). Subsequently, additional intercellular interactions are established and further tighten the cohesion between platelets and tumor cells within TCPAs (Erpenbeck and Schon, 2010).

After initial Clec-2-podoplanin mediated activation, platelets degranulate and expose P-selectin on their cell membranes (Jenne et al., 2013; van Golen et al., 2015). P-selectin on the platelet surface binds to the Sialyl-Lewis ${ }^{x}$-tetrasaccharide conjugate of PSGL-1 (P-selectin glycoprotein ligand-1) expressed on tumor cells, thus constituting a secondary level of platelet-tumor 


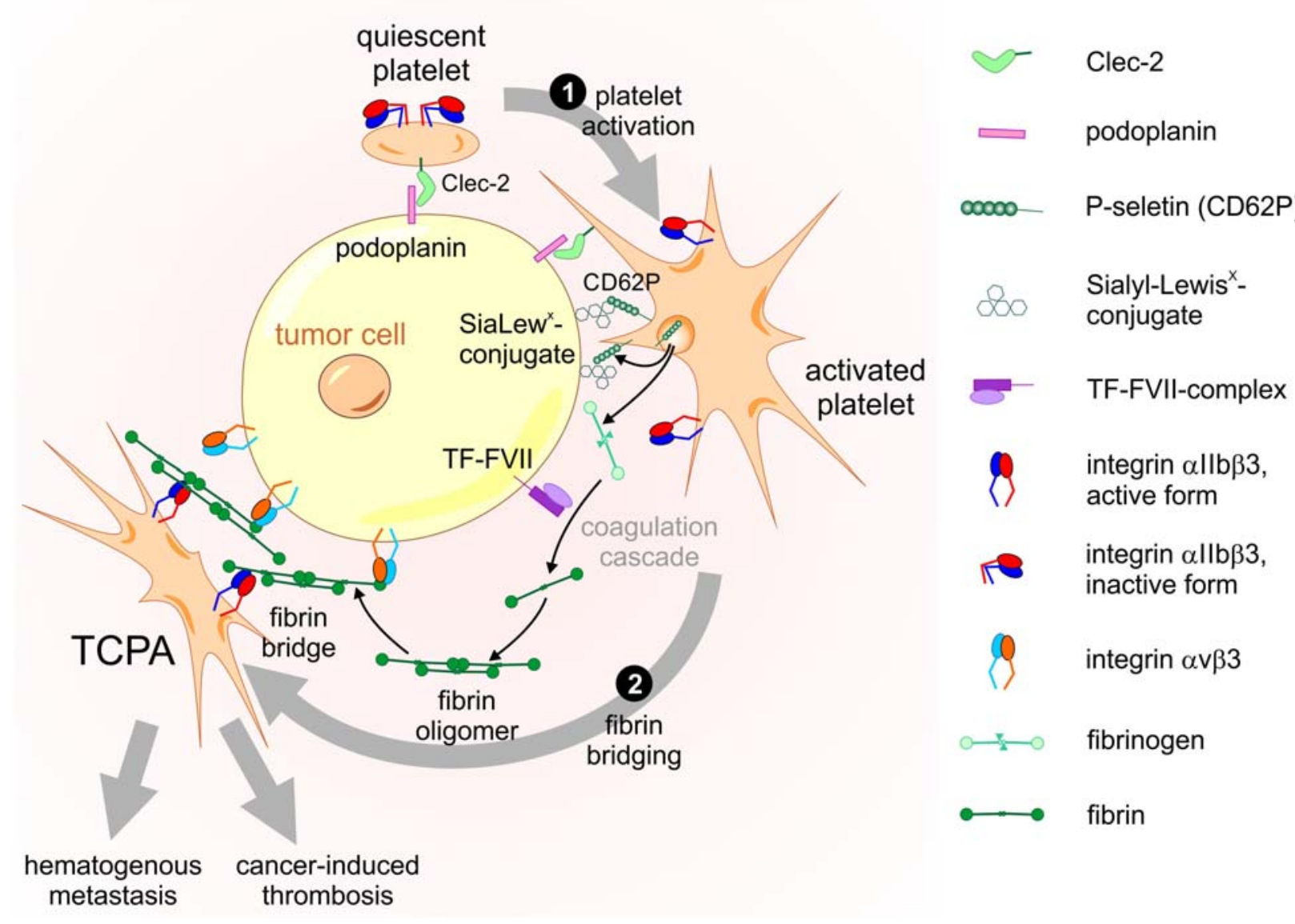

FIGURE 3 | Molecular components and activation steps of the TCPA formation cascade. The cascade of TCPA formation consists at least of the following two steps. (1) Platelet activation triggered by Clec-2-podoplanin interaction results in degranulation with surface exposure of $\mathrm{P}$-selectin, release of fibrinogen and conversion of integrin $\alpha$ llb $\beta 3$ into an active conformation. (2) Fibrin bridging of platelets and tumor cells requires cleavage of fibrinogen to fibrin by the extrinsic coagulation pathway initiated by the TF-FVII complex on tumor cells. Fibrin molecules, aggregated in a network, are bound by $\alpha \mathrm{V} \beta 3$ and $\alpha$ llb $\beta 3$ integrins on tumor cells and platelets, respectively, allowing a stable mechanical bridge within the TCPA.

cell cohesion downstream of the Clec-2-podoplanin interaction (Coupland and Parish, 2014).

Fibrin which is generated from fibrinogen by thrombin serves as another bracket between tumor cells and platelets as it is bound by integrin $\alpha \operatorname{IIb} \beta 3$ on the platelet surface and by integrin $\alpha \mathrm{V} \beta 3$ on the tumor cell, building a firm bridge between the two cell types (Katagiri et al., 1995). While integrin $\alpha$ V $\beta 3$ binds to an RGD motif in the fibrinogen $\alpha$ subunit, integrin $\alpha \operatorname{IIb} \beta 3$ interacts with another peptide sequence in the $\gamma$ subunit (Springer et al., 2008). As a result, platelets and tumor cells firmly cohere to form stable TCPAs connected by three different receptor pairs: Clec- 2 and podoplanin, P-selectin and PSGL-1, and integrin $\alpha \mathrm{IIb} \beta 3$ via fibrin to integrin $\alpha \mathrm{V} \beta 3$ (Figure 3). Moreover, clotting factor FXIII, a transglutaminase, crosslinks plasma fibronectin to insoluble fibrin oligomers, thereby forming a fibrin-fibronectin network (Corbett et al., 1997) and imbedding the metastasizing tumor cell. In addition, the fibrin-fibronectin complex binds to and further activates integrin $\alpha \mathrm{V} \beta 3$ on tumor cells, inducing invadopodia formation and metastasis (Malik et al., 2010). Yet another way of tumor cell-platelet crosstalk has been reported recently. CD97, an adhesion dependent $G$ protein coupled receptor on tumor cells, activates platelets by a so far unknown counterreceptor to release lysophosphatidic acid (LPA) from dense granules (Ward et al., 2018). In turn, LPA binds to its receptor on tumor cells and starts the Rho kinase signaling pathway, which is associated with tumor cell invasiveness (Ward et al., 2018).

A major threat to blood-borne cancer cells during hematogenous metastasis are natural killer cells that clear tumor cells by cytolytic attack (Nieswandt et al., 1999). In the microenvironment of TCPAs, tumor cells exploit platelets to escape their elimination by the immune system (Labelle and Hynes, 2012; Schlesinger, 2018). The presence of MHC (major histocompatibility complex) class I molecules on the surface of a cell indicates "self" to avoid activation of the immune response. Since many tumor cells traveling alone in the blood circulation show no or low expression of $\mathrm{MHC}$ class I molecules on their surface, they are easy prey to natural killer cells (Placke et al., 2012b). In contrast, platelets express plenty of MHC class I molecules on their membrane, which shelters them and the close-by tumor cells within the 
TCPAs (Placke et al., 2012b). These platelet derived MHC class I molecules confer "self" to tumor cells and thereby circumvent destruction by natural killer cells (Placke et al., 2012a). Furthermore, activated platelets release growth factors such as PDGF and TGF $\beta$ from their $\alpha$-granules. PDGF binds to PDGF receptors on the surface of natural killer cells and lowers their cytolytic activity (Gersuk et al., 1991). TGF $\beta$ impedes expression of NKG2D, a C-type lectin-like receptor on natural killer cells that normally detects transformed tumor cells (Kopp et al., 2009). Accordingly, this constricts cytotoxicity of natural killer cells and lowers disposal of interferon- $\gamma$, an antitumorigenic cytokine and stimulator of the immune response (Kopp et al., 2009).

\section{THE ROLE OF PLATELETS IN PREPARING METASTATIC NICHES}

Having escaped the mechanical challenges in the blood circulation and the threat of the immune system, tumor cells in TCPAs receive further support by platelets as they move to their destination site. After floating for some minutes in the bloodstream, TCPAs come to rest at the vasculature of blood vessels, where tumor cells prepare for extravasation (Labelle and Hynes, 2012). To support attachment of their accompanying tumor cells to the vessel wall, activated platelets bind with $\mathrm{P}$-selectins to Sialyl-Lewis ${ }^{\mathrm{x}}$-conjugates on the surface of endothelial cells (Gay and Felding-Habermann, 2011a). Hence, platelets create a custom-made microenvironment to safeguard the tumor cells, help them in tethering to endothelial cells and expedite metastasis in their target tissue (Schlesinger, 2018; Palacios-Acedo et al., 2019; Gkolfinopoulos et al., 2020). Fostering the formation of metastatic niches, activated platelets release a multitude of growth factors, cytokines, ECM proteins and clotting factors, and attract different host derived cells of the myeloid lineage such as neutrophils, monocytes and macrophages to assist the piggy-backed tumor cells (Labelle and Hynes, 2012).

Platelets release cytokines CXCL5 and CXCL7 that bind to the CXCR2 receptor on neutrophils to attract them to the metastatic niche (Labelle et al., 2014; Wu et al., 2019; Jaillon et al., 2020). There, neutrophils bind to tumor cells and enforce their attachment to endothelial cells (Huh et al., 2010). Furthermore, upon stimulation by platelet delivered TGF $\beta$, neutrophils produce reactive oxygen species (ROS), nitric oxide and arginase that prevent stimulation of immune reactive $\mathrm{T}$ cells (Jaillon et al., 2020). In addition, neutrophils release leukotrienes that confer a high tumorigenic and metastatic potential to tumor cells (Wculek and Malanchi, 2015). Moreover, tumor cells in TCPAs induce the secretion of acid sphingomyelinase from platelets, in turn leading to hydrolysis of sphingomyelin to ceramide (Carpinteiro et al., 2015). In the tumor cell, ceramide molecules form membrane domains in which receptor proteins, such as integrin $\alpha 5 \beta 1$, accumulate. Integrin $\alpha 5 \beta 1$ clustering further strengthens attachment of tumor cells to the endothelial wall and thereby promotes their metastatic potential (Carpinteiro et al., 2015).
TGF $\beta$ released from platelets and direct contact between platelets and tumor cells activate TGF $\beta$-Smad and NF- $\mathrm{B}$ pathways, respectively, in tumor cells (Labelle et al., 2011; Labelle and Hynes, 2012). This results in transcription of target genes, which promote transformation of tumor cells from an epithelial to a mesenchymal phenotype (Labelle et al., 2011; Mittal, 2018). Accordingly, synergistic activation of TGF $\beta$-Smad and NF-кB pathways downregulate epithelial markers such as claudin1 and E-cadherin, but lead to upregulation of mesenchymal transcription factors such as snail and twist, and marker proteins including vimentin and fibronectin in tumor cells (Labelle et al., 2011; Mittal, 2018). Moreover, target genes of the NF-кB and TGF $\beta$-Smad signaling pathways, such as Serpin family $\mathrm{H}$ member 1 (SERPINH1), Matrix metalloproteinase 9 (MMP9), Vascular endothelial growth factor C (VEGF-C), Tenascin C (TNC) and C-C motif chemokine 2 (CCL2) enhance hematogenous tumor metastasis by different mechanisms (Labelle et al., 2011; Kim et al., 2019; Xiong F. et al., 2020). For example, during epithelialmesenchymal transition, snail dependent downregulation of E-cadherin results in loss of intercellular contacts between cancer cells, and loss of their original polarized cellular shape and tissue specific properties (Mittal, 2018). Therefore, tumor cells become mobile, allowing migration and extravasation through the endothelial barrier. Tumor cell overexpressed SERPINH1 encodes the endoplasmic reticulum resident heat shock protein 47 (Hsp47), a molecular chaperone that fosters collagen type I production and export through the secretory pathway during epithelial-mesenchymal transition (Xiong G. et al., 2020). This results in the collagen-rich desmoplastic TME also at the metastatic site. Accordingly, collagen enforces recruitment of platelets to tumor cells, thereby facilitating migration through the endothelium and induces interaction of tumor cells and cluster formation, a necessity for metastasis (Xiong F. et al., 2020). MMP9 is required for ECM remodeling, while VEGF-C and TNC are involved in endothelial cell growth and angiogenesis (Carmeliet, 2005; Rupp et al., 2016). CCL2 released from tumor cells after platelet stimulation is the ligand for chemokine receptor 2 (CCR2) expressed on monocytes and endothelial cells (Wolf et al., 2012). CCL2 binding attracts monocytes to tumor cells and confers suppression of the immune response (Mantovani and Sica, 2010). Stimulation of endothelial cells by CCL2 increases cell permeability of the endothelial wall and tumor cell extravasation by signaling via Janus kinase 2 (JAK2), which triggers downstream signal transducer and activator of transcription 5 (Stat5) and p38 mitogen-activated protein kinase (p38MAPK) activation (Wolf et al., 2012). Eventually, tumor cells that have acquired a mesenchymal, mobile phenotype break the endothelial barrier and make their way to form metastases at distant organs.

\section{PERSPECTIVES FOR TRANSLATION INTO CLINICAL TREATMENT STRATEGIES}

Platelets and coagulation play a crucial role in tumor progression and hematogenous metastasis and are therefore considered as 
valid pharmaceutical targets in anti-cancer therapy (Zhang et al., 2020). The important surveillance of platelet counts during chemotherapy, their role in chemoresitance, and the potential use of platelets as drug delivery systems in chemotherapy have recently been reviewed (Swier and Versteeg, 2017; Dovizio et al., 2020; Zhang et al., 2020). Therefore, we will not focus on this platelet-dependent aspect of chemotherapy, but will here focus on targeting platelets as relevant constituents of the TME. With respect to the TME of solid tumor mass, different strategies have been chosen to target platelets and tumor cell-induced coagulation. Interestingly, a monoclonal antibody inhibiting TF-signaling via PAR2 reduces tumor growth, while another TF-directed antibody that inhibits its proteolytic function only impedes hematogenous metastasis (Versteeg et al., 2008). Another monoclonal antibody, CNTO 859 , inhibits both progression and hematogenous metastasis of tumor cells (Ngo et al., 2007). Two recombinant anticoagulant proteins, the nematode anticoagulant protein $\mathrm{c} 2$ (NAPc2) and ixolaris from a tick species, both targeting the TF:FVII complex reduce also tumor progression and metastasis (Hembrough et al., 2003; Carneiro-Lobo et al., 2009). However, it is not entirely clear yet, which isoform of TF influences which steps of tumor progression and metastasis and via which mechanism (van den Berg et al., 2012). Also, TF-positive microvesicles are intensely studied as potential targets to reduce tumor-induced thrombosis and metastasis (Rondon et al., 2019).

Instead of inhibiting TF, another therapeutic approach utilizes TF to pharmaceutically induce tumor infarction. To this end, recombinant $\mathrm{TF}$ is directed to tumor vessels either in a soluble form or bound to nanoparticles (Schwöppe et al., 2010; Ding et al., 2013; Schliemann et al., 2020). By enriching TF in the tumor vessels, an excessive fibrin deposition and thrombus formation occlude the tumor vasculature (Jahanban-Esfahlan et al., 2017). The resulting hemostatic plug abolishes the blood flow and the nutrient support for the tumor, resulting in tumor infarction and regression of tumor tissue (Schliemann et al., 2020).

Targeting adhesion and infiltration of platelets within the TME of solid tumors is also tested as potential strategy to curb tumor progression. To this end, adhesive platelet receptors are molecular targets, especially as they have already been clinically addressed to treat thrombosis. RGD-mimicking compounds that interfere with ligand binding of both platelet integrin $\alpha \operatorname{IIb} \beta 3$ and $\alpha \mathrm{V} \beta 3$ on tumor cells are relevant lead structures for antitumor applications (Jamasbi et al., 2017; Miller et al., 2017). Their inhibitory mechanism and efficacy on RGD-dependent integrins have been derived from snake venom disintegrins (Huang et al., 2016; Estevao-Costa et al., 2018). Another toxin class from snake venoms, the C-type lectin-related proteins, are very efficient inhibitors specifically directed to the receptors for collagen and vWF (Eble, 2019).

The contact of quiescent platelets with blood-borne tumor cells initiates the formation of TCPAs, giving rise to hematogenous metastasis and cancer-induced thrombosis. Therefore, it is of upmost importance to interfere with this initial step of platelet activation right at the beginning (Figure 3). Since the primary contact between tumor cells and platelets likely is mediated by the Clec-2-podoplanin interaction, targeting this early step should substantially impede the entire TCPA formation cascade. Accordingly, several approaches are being followed to identify inhibitors of Clec-2 and podoplanin (Harbi et al., 2021). Among the Clec-2 targeting toxins, the snake venom rhodocytin, also named aggretin, was the first to be discovered (Suzuki-Inoue et al., 2006). It is a heterodimeric C-type lectin from the Malayan pit viper Calloselasma rhodostoma consisting of $\alpha$ and $\beta$ chains covalently linked by a disulfide bridge. Crystal structure analysis identified rhodocytin as a $(\alpha \beta)_{2}$ heterotetramer that binds to Clec-2, induces receptor clustering on the cell surface and thereby triggers platelet activation and aggregation (Watson et al., 2008). Mutations introduced into recombinant rhodocytin expressed in E. coli preserved heterodimer formation but disturbed the oligomeric suprastructure of rhodocytin (Sasaki et al., 2018). Remarkably, such rhodocytin mutant still binds to Clec-2 but fails to induce receptor clustering, thereby blocking the Clec-2-podoplanin axis and platelet activation (Sasaki et al., 2018). Furthermore, when tested in a mouse model of podoplanin-induced lung cancer, mutant rhodocytin prevented formation of metastases, demonstrating that change of its suprastructure can turn rhodocytin from an agonist to an antagonist of tumor cell-induced platelet aggregation and TCPA formation (Sasaki et al., 2018). Since protein medications are rather circumstantial to administer, small drug-like compounds are another approach that was followed to disrupt the Clec2-podoplanin axis. Cobalt hematoporphyrin was identified by screening a chemical compound library for inhibitors of the interaction between recombinant expressed Clec-2 and podoplanin (Tsukiji et al., 2018). When cobalt hematoporphyrin was used in a mouse model, podoplanin-induced pulmonary metastasis was blocked efficiently (Tsukiji et al., 2018), however, at a potency yet too low for clinical application (Harbi et al., 2021). In a similar approach the 5 -nitrobenzoate compound $2 \mathrm{CP}$ was discovered as another inhibitor of the Clec-2-podoplanin interaction (Chang et al., 2015). 2CP suppressed pulmonary tumor metastasis in a xenograft mouse model, although at concentrations yet too high for clinical use (Chang et al., 2015).

Another strategy to interfere with Clec-2-podoplanin mediated TCPA formation may be function-blocking antibodies. The mouse monoclonal antibody AYP1 specifically recognizes human Clec-2 and perturbs activation and aggregation of platelets upon stimulation with podoplanin or snake venom rhodocytin (Gitz et al., 2014). However, no in vivo study to test this antibody in cancer metastasis has been reported so far. Likewise, monoclonal antibodies 8.1.1 and SZ168 were raised against podoplanin that block the interaction with Clec-2 and platelet activation (Rayes et al., 2017; Wang et al., 2021). When used in a mouse model, podoplanin antibody SZ168 repressed podoplanin dependent, cancer associated thrombosis (Wang et al., 2021).

These preliminary data indicate that the TME provided by the recruitment of platelets to a solid tumor mass or to bloodborne cancer cells is a valid target to curb tumor progression and metastasis. Newly developed tools targeting the multiple platelettumor cell interactions may open new strategies not only to reduce the fatal consequence of the Trousseau syndrome but also to impede tumor growth and dissemination. 


\section{AUTHOR CONTRIBUTIONS}

WO and JE drafted and wrote the manuscript. KB helped in search for references and edited the manuscript. All authors contributed to the article and approved the submitted version.

\section{FUNDING}

This work was financially supported by the University of Münster through the Interdisciplinary Center of Clinical

\section{REFERENCES}

Acerbi, I., Cassereau, L., Dean, I., Shi, Q., Au, A., Park, C., et al. (2015). Human breast cancer invasion and aggression correlates with ECM stiffening and immune cell infiltration. Integr. Biol. (Camb) 7, 1120-1134. doi: 10.1039/ c5ib00040h

Andonegui-Elguera, M. A., Alfaro-Mora, Y., Caceres-Gutierrez, R., Caro-Sanchez, C. H. S., Herrera, L. A., and Diaz-Chavez, J. (2020). An overview of vasculogenic mimicry in Breast Cancer. Front. Oncol. 10:220. doi: 10.3389/fonc.2020.00220

Andrews, R. K., and Berndt, M. C. (2004). Platelet physiology and thrombosis. Thromb. Res. 114, 447-453. doi: 10.1016/j.thromres.2004.07.020

Andrews, R. K., and Berndt, M. C. (2008). Platelet adhesion: a game of catch and release. J. Clin. Invest. 118, 3009-3011.

Andrews, R. K., Gardiner, E. E., Shen, Y., Whisstock, J. C., and Berndt, M. C. (2003). Glycoprotein Ib-IX-V. Int. J. Biochem. Cell Biol. 35, 1170-1174.

Apte, R. S., Chen, D. S., and Ferrara, N. (2019). VEGF in signaling and disease: beyond discovery and development. Cell 176, 1248-1264. doi: 10.1016/j.cell. 2019.01.021

Arnaout, M. A., Mahalingam, B., and Xiong, J. P. (2005). Integrin structure, allostery, and bidirectional signaling. Annu. Rev. Cell Dev. Biol. 21, 381-410. doi: 10.1146/annurev.cellbio.21.090704.151217

Arthur, J. F., Gardiner, E. E., Matzaris, M., Taylor, S. G., Wijeyewickrema, L., Ozaki, Y., et al. (2005). Glycoprotein VI is associated with GPIb-IX-V on the membrane of resting and activated platelets. Thromb. Haemost. 93, 716-723. doi: 10.1160/th04-09-0584

Atkinson, B. T., Jarvis, G. E., and Watson, S. P. (2003). Activation of GPVI by collagen is regulated by alpha2betal and secondary mediators. J. Thromb. Haemost. 1, 1278-1287. doi: 10.1046/j.1538-7836.2003.00245.x

Benazzi, C., Al-Dissi, A., Chau, C. H., Figg, W. D., Sarli, G., De Oliveira, J. T., et al. (2014). Angiogenesis in spontaneous tumors and implications for comparative tumor biology. ScientificWorldJournal 2014:919570.

Berndt, M. C., Metharom, P., and Andrews, R. K. (2014). Primary haemostasis: newer insights. Haemophilia 20(Suppl. 4), 15-22. doi: 10.1111/hae.12427

Bikfalvi, A., and Billottet, C. (2020). The CC and CXC chemokines: major regulators of tumor progression and the tumor microenvironment. Am. J. Physiol. Cell Physiol. 318, C542-C554.

Broos, K., De Meyer, S. F., Feys, H. B., Vanhoorelbeke, K., and Deckmyn, H. (2012). Blood platelet biochemistry. Thromb. Res. 129, 245-249. doi: 10.1016/j. thromres.2011.11.002

Burbury, K., and MacManus, M. P. (2018). The coagulome and the oncomir: impact of cancer-associated haemostatic dysregulation on the risk of metastasis. Clin. Exp. Metastasis 35, 237-246. doi: 10.1007/s10585-018-9875-0

Callander, N. S., Varki, N., and Rao, L. V. (1992). Immunohistochemical identification of tissue factor in solid tumors. Cancer 70, 1194-1201. doi: 10.1002/1097-0142(19920901)70:5<1194::aid-cncr2820700528>3.0.co;2-e

Camire, R. M. (2016). Rethinking events in the haemostatic process: role of factor V and TFPI. Haemophilia 22(Suppl. 5), 3-8. doi: 10.1111/hae.13004

Campello, E., Henderson, M. W., Noubouossie, D. F., Simioni, P., and Key, N. S. (2018). Contact system activation and cancer: new insights in the pathophysiology of Cancer-Associated thrombosis. Thromb. Haemost. 118, 251-265. doi: 10.1160/th17-08-0596

Carmeliet, P. (2005). VEGF as a key mediator of angiogenesis in cancer. Oncology 69(Suppl. 3), 4-10. doi: 10.1159/000088478
Research (IZKF) (IZKF-grant: Ebl/009/21 to JE) and by the Deutsche Forschungsgemeinschaft (DFG) through the SFB1009 project A09 and DFG-grant Eb177/17-1 to JE.

\section{ACKNOWLEDGMENTS}

We apologize to all researchers whose scientific contributions are not cited due to the length restrictions.

Carneiro-Lobo, T. C., Konig, S., Machado, D. E., Nasciutti, L. E., Forni, M. F. Francischetti, I. M., et al. (2009). Ixolaris, a tissue factor inhibitor, blocks primary tumor growth and angiogenesis in a glioblastoma model. J. Thromb. Haemost. 7, 1855-1864. doi: 10.1111/j.1538-7836.2009.03553.x

Carpinteiro, A., Becker, K. A., Japtok, L., Hessler, G., Keitsch, S., Pozgajova, M., et al. (2015). Regulation of hematogenous tumor metastasis by acid sphingomyelinase. EMBO Mol. Med. 7, 714-734. doi: 10.15252/emmm. 201404571

Cedervall, J., Hamidi, A., and Olsson, A. K. (2018). Platelets. NETs and cancer. Thromb. Res. 164(Suppl. 1), S148-S152.

Chang, Y. W., Hsieh, P. W., Chang, Y. T., Lu, M. H., Huang, T. F., Chong, K. Y., et al. (2015). Identification of a novel platelet antagonist that binds to CLEC-2 and suppresses podoplanin-induced platelet aggregation and cancer metastasis. Oncotarget 6, 42733-42748. doi: 10.18632/oncotarget.5811

Chen, Y., Ruggeri, Z. M., and Du, X. (2018). 14-3-3 proteins in platelet biology and glycoprotein Ib-IX signaling. Blood 131, 2436-2448. doi: 10.1182/blood-201709- 742650

Chouaib, S., Kieda, C., Benlalam, H., Noman, M. Z., Mami-Chouaib, F., and Ruegg, C. (2010). Endothelial cells as key determinants of the tumor microenvironment: interaction with tumor cells, extracellular matrix and immune killer cells. Crit. Rev. Immunol. 30, 529-545. doi: 10.1615/ critrevimmunol.v30.i6.30

Chowdary, P. (2020). Anti-tissue factor pathway inhibitor (TFPI) therapy: a novel approach to the treatment of haemophilia. Int. J. Hematol. 111, 42-50. doi: 10.1007/s12185-018-2548-6

Coller, B. S. (2015). alphaIIbbeta3: structure and function. J. Thromb. Haemost. 13(Suppl. 1), S17-S25.

Connolly, G. C., and Francis, C. W. (2013). Cancer-associated thrombosis. Hematol. Am. Soc. Hematol. Educ. Program 2013, 684-691.

Corbett, S. A., Lee, L., Wilson, C. L., and Schwarzbauer, J. E. (1997). Covalent cross-linking of fibronectin to fibrin is required for maximal cell adhesion to a fibronectin-fibrin matrix. J. Biol. Chem. 272, 24999-25005. doi: 10.1074/jbc. 272.40.24999

Coupland, L. A., and Parish, C. R. (2014). Platelets, selectins, and the control of tumor metastasis. Semin. Oncol. 41, 422-434. doi: 10.1053/j.seminoncol.2014 04.003

Dahlbäck, B. (2000). Blood coagulation. Lancet 355, 1627-1632.

Dahlback, B. (2017). Novel insights into the regulation of coagulation by factor $\mathrm{V}$ isoforms, tissue factor pathway inhibitoralpha, and protein S. J. Thromb. Haemost. 15, 1241-1250. doi: 10.1111/jth.13665

De Palma, M., Biziato, D., and Petrova, T. V. (2017). Microenvironmental regulation of tumour angiogenesis. Nat. Rev. Cancer 17, 457-474. doi: 10.1038/ nrc. 2017.51

de Witt, S. M., Verdoold, R., Cosemans, J. M., and Heemskerk, J. W. (2014). Insights into platelet-based control of coagulation. Thromb. Res. 133(Suppl. 2), S139-S148.

Ding, Y., Li, S., and Nie, G. (2013). Nanotechnological strategies for therapeutic targeting of tumor vasculature. Nanomedicine (Lond) 8, 1209-1222. doi: 10 . 2217/nnm.13.106

Dovizio, M., Ballerini, P., Fullone, R., Tacconelli, S., Contursi, A., and Patrignani, P. (2020). Multifaceted functions of platelets in Cancer: from tumorigenesis to liquid biopsy tool and drug delivery system. Int. J. Mol. Sci. 21, 9585. doi: 10.3390/ijms21249585 
Durrant, T. N., Van Den Bosch, M. T., and Hers, I. (2017). Integrin alphaIIbbeta3 outside-in signaling. Blood 130, 1607-1619.

Eble, J. A. (2005). Collagen-binding integrins as pharmaceutical targets. Curr. Pharm. Des 11, 867-880. doi: 10.2174/1381612053381738

Eble, J. A. (2019). structurally robust and functionally highly Versatile-C-Type Lectin (-Related) proteins in snake venoms. Toxins (Basel) 11:136. doi: 10.3390/ toxins 11030136

Eble, J. A., and Niland, S. (2019). The extracellular matrix in tumor progression and metastasis. Clin. Exp. Metastasis 36, 171-198. doi: 10.1007/s10585-019-09966- 1

Egan, K., Cooke, N., and Kenny, D. (2014). Living in shear: platelets protect cancer cells from shear induced damage. Clin. Exp. Metastasis 31, 697-704. doi: 10.1007/s10585-014-9660-7

Emsley, J., Knight, C. G., Farndale, R. W., Barnes, M. J., and Liddington, R. C. (2000). Structural basis of collagen recognition by integrin alpha2beta1. Cell 101, 47-56. doi: 10.1016/s0092-8674(00)80622-4

Erpenbeck, L., and Schon, M. P. (2010). Deadly allies: the fatal interplay between platelets and metastasizing cancer cells. Blood 115, 3427-3436. doi: 10.1182/ blood-2009-10-247296

Erpenbeck, L., and Schon, M. P. (2017). Neutrophil extracellular traps: protagonists of cancer progression? Oncogene 36, 2483-2490. doi: 10.1038/onc.2016.406

Estevao-Costa, M. I., Sanz-Soler, R., Johanningmeier, B., and Eble, J. A. (2018). Snake venom components in medicine: from the symbolic rod of Asclepius to tangible medical research and application. Int. J. Biochem. Cell Biol. 104, 94-113. doi: 10.1016/j.biocel.2018.09.011

Fitzgerald, G., Soro-Arnaiz, I., and De Bock, K. (2018). The warburg effect in endothelial cells and its potential as an anti-angiogenic target in Cancer. Front. Cell Dev. Biol. 6:100. doi: 10.3389/fcell.2018.00100

Gale, A. J. (2011). Continuing education course \#2: current understanding of hemostasis. Toxicol. Pathol. 39, 273-280.

Gay, L. J., and Felding-Habermann, B. (2011a). Contribution of platelets to tumour metastasis. Nat. Rev. Cancer 11, 123-134. doi: 10.1038/nrc3004

Gay, L. J., and Felding-Habermann, B. (2011b). Platelets alter tumor cell attributes to propel metastasis: programming in transit. Cancer Cell 20, 553-554. doi: 10.1016/j.ccr.2011.11.001

Gersuk, G. M., Westermark, B., Mohabeer, A. J., Challita, P. M., Pattamakom, S., and Pattengale, P. K. (1991). Inhibition of human natural killer cell activity by platelet-derived growth factor (PDGF). III. Membrane binding studies and differential biological effect of recombinant PDGF isoforms. Scand. J. Immunol. 33, 521-532. doi: 10.1111/j.1365-3083.1991.tb02522.x

Gitz, E., Pollitt, A. Y., Gitz-Francois, J. J., Alshehri, O., Mori, J., Montague, S., et al. (2014). CLEC-2 expression is maintained on activated platelets and on platelet microparticles. Blood 124, 2262-2270. doi: 10.1182/blood-2014-05-572818

Gkolfinopoulos, S., Jones, R. L., and Constantinidou, A. (2020). The emerging role of platelets in the formation of the micrometastatic niche: current evidence and future perspectives. Front. Oncol. 10:374. doi: 10.3389/fonc.2020.00374

Goubran, H., Sabry, W., Kotb, R., Seghatchian, J., and Burnouf, T. (2015). Platelet microparticles and cancer: an intimate cross-talk. Transfus Apher Sci. 53, 168-172. doi: 10.1016/j.transci.2015.10.014

Grassle, S., Huck, V., Pappelbaum, K. I., Gorzelanny, C., Aponte-Santamaria, C., Baldauf, C., et al. (2014). von Willebrand factor directly interacts with DNA from neutrophil extracellular traps. Arterioscler. Thromb. Vasc. Biol. 34, 1382-1389. doi: 10.1161/atvbaha.113.303016

Grover, S. P., and Mackman, N. (2018). Tissue factor: an essential mediator of hemostasis and trigger of thrombosis. Arterioscler. Thromb. Vasc. Biol. 38, 709-725. doi: 10.1161/atvbaha.117.309846

Haling, J. R., Monkley, S. J., Critchley, D. R., and Petrich, B. G. (2011). Talindependent integrin activation is required for fibrin clot retraction by platelets. Blood 117, 1719-1722. doi: 10.1182/blood-2010-09-305433

Hamaia, S., and Farndale, R. W. (2014). Integrin recognition motifs in the human collagens. Adv. Exp. Med. Biol. 819, 127-142. doi: 10.1007/978-94-017-915339

Han, X., Guo, B., Li, Y., and Zhu, B. (2014). Tissue factor in tumor microenvironment: a systematic review. J. Hematol. Oncol. 7:54.

Hanein, D., and Volkmann, N. (2018). Conformational equilibrium of human platelet integrin investigated by three-dimensional electron cryo-microscopy. Subcell Biochem. 87, 353-363. doi: 10.1007/978-981-10-7757-9_12
Hansen, C. E., Qiu, Y., Mccarty, O. J. T., and Lam, W. A. (2018). Platelet mechanotransduction. Annu. Rev. Biomed. Eng. 20, 253-275. doi: 10.1146/ annurev-bioeng-062117-121215

Harbi, M. H., Smith, C. W., Nicolson, P. L. R., Watson, S. P., and Thomas, M. R. (2021). Novel antiplatelet strategies targeting GPVI. CLEC-2 and tyrosine kinases. Platelets 32, 29-41. doi: 10.1080/09537104.2020.1849600

He, L., Pappan, L. K., Grenache, D. G., Li, Z., Tollefsen, D. M., Santoro, S. A., et al. (2003). The contributions of the alpha 2 beta 1 integrin to vascular thrombosis in vivo. Blood 102, 3652-3657.

Hembrough, T. A., Swartz, G. M., Papathanassiu, A., Vlasuk, G. P., Rote, W. E., Green, S. J., et al. (2003). Tissue factor/factor VIIa inhibitors block angiogenesis and tumor growth through a nonhemostatic mechanism. Cancer Res. 63, 2997-3000.

Henke, E., Nandigama, R., and Ergun, S. (2019). Extracellular matrix in the tumor microenvironment and its impact on Cancer therapy. Front. Mol. Biosci. 6:160. doi: $10.3389 / \mathrm{fmolb} .2019 .00160$

Huang, J., Li, X., Shi, X., Zhu, M., Wang, J., Huang, S., et al. (2019). Platelet integrin alphaIIbbeta3: signal transduction, regulation, and its therapeutic targeting. J. Hematol. Oncol. 12:26.

Huang, T. F., Hsu, C. C., and Kuo, Y. J. (2016). Anti-thrombotic agents derived from snake venom proteins. Thromb. J. 14:18.

Huber, M., Brehm, C. U., Gress, T. M., Buchholz, M., Alashkar Alhamwe, B., Von Strandmann, E. P., et al. (2020). The immune microenvironment in pancreatic Cancer. Int. J. Mol. Sci. 21:7307.

Huck, V., Schneider, M. F., Gorzelanny, C., and Schneider, S. W. (2014). The various states of von willebrand factor and their function in physiology and pathophysiology. Thromb. Haemost. 111, 598-609. doi: 10.1160/th13-090800

Hughes, C. E., Sinha, U., Pandey, A., Eble, J. A., O'callaghan, C. A., and Watson, S. P. (2013). Critical Role for an acidic amino acid region in platelet signaling by the HemITAM (hemi-immunoreceptor tyrosine-based activation motif) containing receptor CLEC-2 (C-type lectin receptor-2). J. Biol. Chem. 288, 5127-5135. doi: $10.1074 / j b c . m 112.411462$

Huh, S. J., Liang, S., Sharma, A., Dong, C., and Robertson, G. P. (2010). Transiently entrapped circulating tumor cells interact with neutrophils to facilitate lung metastasis development. Cancer Res. 70, 6071-6082. doi: 10.1158/0008-5472. can-09-4442

Humphries, J. D., Chastney, M. R., Askari, J. A., and Humphries, M. J. (2019). Signal transduction via integrin adhesion complexes. Curr. Opin. Cell Biol. 56, 14-21. doi: 10.1016/j.ceb.2018.08.004

Inoue, O., Suzuki-Inoue, K., Dean, W. L., Frampton, J., and Watson, S. P. (2003). Integrin alpha2betal mediates outside-in regulation of platelet spreading on collagen through activation of Src kinases and PLCgamma2. J. Cell Biol. 160, 769-780. doi: $10.1083 /$ jcb.200208043

Iozzo, R. V., and Sanderson, R. D. (2011). Proteoglycans in cancer biology, tumour microenvironment and angiogenesis. J. Cell Mol. Med. 15, 1013-1031. doi: 10.1111/j.1582-4934.2010.01236.x

Izquierdo, I., Barrachina, M. N., Hermida-Nogueira, L., Casas, V., Moran, L. A., Lacerenza, S., et al. (2020). A comprehensive tyrosine phosphoproteomic analysis reveals novel components of the platelet CLEC-2 signaling cascade. Thromb. Haemost. 120, 262-276. doi: 10.1055/s-0039-3400295

Jahanban-Esfahlan, R., Seidi, K., and Zarghami, N. (2017). Tumor vascular infarction: prospects and challenges. Int. J. Hematol. 105, 244-256. doi: 10. 1007/s12185-016-2171-3

Jaillon, S., Ponzetta, A., Di Mitri, D., Santoni, A., Bonecchi, R., and Mantovani, A. (2020). Neutrophil diversity and plasticity in tumour progression and therapy. Nat. Rev. Cancer 20, 485-503. doi: 10.1038/s41568-020-0281-y

Jamasbi, J., Ayabe, K., Goto, S., Nieswandt, B., Peter, K., and Siess, W. (2017). Platelet receptors as therapeutic targets: past, present and future. Thromb. Haemost. 117, 1249-1257. doi: 10.1160/th16-12-0911

Jarvis, G. E., Best, D., and Watson, S. P. (2004). Differential roles of integrins alpha2beta1 and alphaIIbbeta3 in collagen and CRP-induced platelet activation. Platelets 15, 303-313. doi: 10.1080/09537100410001710254

Jenne, C. N., Urrutia, R., and Kubes, P. (2013). Platelets: bridging hemostasis, inflammation, and immunity. Int. J. Lab. Hematol. 35, 254-261. doi: 10.1111/ ijlh.12084 
Jennewein, C., Tran, N., Paulus, P., Ellinghaus, P., Eble, J. A., and Zacharowski, K. (2011). Novel aspects of fibrin(ogen) fragments during inflammation. Mol. Med. 17, 568-573. doi: 10.2119/molmed.2010.00146

Kalluri, R. (2016). The biology and function of fibroblasts in cancer. Nat. Rev. Cancer 16, 582-598. doi: 10.1038/nrc.2016.73

Kaneko, M. K., Kato, Y., Kameyama, A., Ito, H., Kuno, A., Hirabayashi, J., et al. (2007). Functional glycosylation of human podoplanin: glycan structure of platelet aggregation-inducing factor. FEBS Lett. 581, 331-336. doi: 10.1016/j. febslet.2006.12.044

Kania, A., and Klein, R. (2016). Mechanisms of ephrin-Eph signalling in development, physiology and disease. Nat. Rev. Mol. Cell Biol. 17, 240-256. doi: $10.1038 / \mathrm{nrm} .2015 .16$

Kasirer-Friede, A., Kang, J., Kahner, B., Ye, F., Ginsberg, M. H., and Shattil, S. J. (2014). ADAP interactions with talin and kindlin promote platelet integrin alphaIIbbeta3 activation and stable fibrinogen binding. Blood 123, 3156-3165. doi: 10.1182/blood-2013-08-520627

Katagiri, Y., Hiroyama, T., Akamatsu, N., Suzuki, H., Yamazaki, H., and Tanoue, K. (1995). Involvement of alpha v beta 3 integrin in mediating fibrin gel retraction. J. Biol. Chem. 270, 1785-1790. doi: 10.1074/jbc.270.4.1785

Kato, K., Kanaji, T., Russell, S., Kunicki, T. J., Furihata, K., Kanaji, S., et al. (2003). The contribution of glycoprotein VI to stable platelet adhesion and thrombus formation illustrated by targeted gene deletion. Blood 102, 1701-1707. doi: 10.1182/blood-2003-03-0717

Kim, H. J., Park, J. H., Shin, J. M., Yang, H. W., Lee, H. M., and Park, I. H. (2019). TGF-beta1-induced HSP47 regulates extracellular matrix accumulation via Smad2/3 signaling pathways in nasal fibroblasts. Sci. Rep. 9:15563.

Klein, D. (2018). The tumor vascular endothelium as decision maker in Cancer therapy. Front. Oncol. 8:367. doi: 10.3389/fonc.2018.00367

Knight, C. G., Morton, L. F., Onley, D. J., Peachey, A. R., Ichinohe, T., Okuma, M., et al. (1999). Collagen-platelet interaction: Gly-Pro-Hyp is uniquely specific for platelet Gp VI and mediates platelet activation by collagen. Cardiovasc. Res. 41, 450-457. doi: 10.1016/s0008-6363(98)00306-x

Kopp, H. G., Placke, T., and Salih, H. R. (2009). Platelet-derived transforming growth factor-beta down-regulates NKG2D thereby inhibiting natural killer cell antitumor reactivity. Cancer Res. 69, 7775-7783. doi: 10.1158/0008-5472.can09-2123

Kuczynski, E. A., Vermeulen, P. B., Pezzella, F., Kerbel, R. S., and Reynolds, A. R. (2019). Vessel co-option in cancer. Nat. Rev. Clin. Oncol. 16, 469-493. doi: 10.1038/s41571-019-0181-9

Kühn, K., and Eble, J. (1994). The structural bases of integrin-ligand interactions. Trends Cell Biol. 4, 256-261. doi: 10.1016/0962-8924(94)90124-4

Kulkarni, S., Dopheide, S. M., Yap, C. L., Ravanat, C., Freund, M., Mangin, P., et al. (2000). A revised model of platelet aggregation. J. Clin. Invest. 105, 783-791.

Kunicki, T. J. (2001). The role of platelet collagen receptor (glycoprotein Ia/IIa; integrin alpha2 beta1) polymorphisms in thrombotic disease. Curr. Opin. Hematol. 8, 277-285. doi: 10.1097/00062752-200109000-00003

Kunicki, T. J., Cheli, Y., Moroi, M., and Furihata, K. (2005). The influence of $\mathrm{N}$-linked glycosylation on the function of platelet glycoprotein VI. Blood 106, 2744-2749. doi: 10.1182/blood-2005-04-1454

Kwaan, H. C., and Lindholm, P. F. (2019). Fibrin and fibrinolysis in Cancer. Semin. Thromb. Hemost. 45, 413-422.

Labelle, M., Begum, S., and Hynes, R. O. (2011). Direct signaling between platelets and cancer cells induces an epithelial-mesenchymal-like transition and promotes metastasis. Cancer Cell 20, 576-590. doi: 10.1016/j.ccr.2011. 09.009

Labelle, M., Begum, S., and Hynes, R. O. (2014). Platelets guide the formation of early metastatic niches. Proc. Natl. Acad. Sci. U S A. 111, E3053-E3061.

Labelle, M., and Hynes, R. O. (2012). The initial hours of metastasis: the importance of cooperative host-tumor cell interactions during hematogenous dissemination. Cancer Discov. 2, 1091-1099. doi: 10.1158/2159-8290.cd-120329

Lancellotti, S., Sacco, M., Basso, M., and De Cristofaro, R. (2019). Mechanochemistry of von Willebrand factor. Biomol Concepts 10, 194-208. doi: 10.1515/bmc-2019-0022

Leight, J. L., Drain, A. P., and Weaver, V. M. (2017). Extracellular matrix remodeling and stiffening modulate tumor phenotype and treatment response.
Ann. Rev. Cancer Biol. 1, 313-334. doi: 10.1146/annurev-cancerbio-050216034431

Li, H., Deng, Y., Sun, K., Yang, H., Liu, J., Wang, M., et al. (2017). Structural basis of kindlin-mediated integrin recognition and activation. Proc. Natl. Acad. Sci. U S A. 114, 9349-9354. doi: 10.1073/pnas.1703064114

Lima, A. M., Wegner, S. V., Martins Cavaco, A. C., Estevao-Costa, M. I., SanzSoler, R., Niland, S., et al. (2018). The spatial molecular pattern of integrin recognition sites and their immobilization to colloidal nanobeads determine alpha2beta1 integrin-dependent platelet activation. Biomaterials 167, 107-120. doi: 10.1016/j.biomaterials.2018.03.028

Liu, Y., Jiang, P., Capkova, K., Xue, D., Ye, L., Sinha, S. C., et al. (2011). Tissue factor-activated coagulation cascade in the tumor microenvironment is critical for tumor progression and an effective target for therapy. Cancer Res. 71, 6492-6502. doi: 10.1158/0008-5472.can-11-1145

Lodyga, M., and Hinz, B. (2020). TGF-betal - a truly transforming growth factor in fibrosis and immunity. Semin. Cell Dev. Biol. 101, 123-139. doi: 10.1016/j. semcdb.2019.12.010

Lof, A., Muller, J. P., and Brehm, M. A. (2018). A biophysical view on von Willebrand factor activation. J. Cell. Physiol. 233, 799-810. doi: 10.1002/jcp. 25887

Luo, B. H., Carman, C. V., and Springer, T. A. (2007). Structural basis of integrin regulation and signaling. Annu. Rev. Immunol. 25, 619-647. doi: 10.1146/ annurev.immunol.25.022106.141618

Madamanchi, A., Santoro, S. A., and Zutter, M. M. (2014). alpha2beta1 Integrin. Adv. Exp. Med. Biol. 819, 41-60.

Malik, G., Knowles, L. M., Dhir, R., Xu, S., Yang, S., Ruoslahti, E., et al. (2010). Plasma fibronectin promotes lung metastasis by contributions to fibrin clots and tumor cell invasion. Cancer Res. 70, 4327-4334. doi: 10.1158/0008-5472. can-09-3312

Mantovani, A., and Sica, A. (2010). Macrophages, innate immunity and cancer: balance, tolerance, and diversity. Curr. Opin. Immunol. 22, 231-237. doi: 10. 1016/j.coi.2010.01.009

Marjoram, R. J., Li, Z., He, L., Tollefsen, D. M., Kunicki, T. J., Dickeson, S. K., et al. (2014). alpha2betal integrin, GPVI receptor, and common FcRgamma chain on mouse platelets mediate distinct responses to collagen in models of thrombosis. PLoS One 9:e114035. doi: 10.1371/journal.pone.0114035

Martins Cavaco, A. C., Damaso, S., Casimiro, S., and Costa, L. (2020). Collagen biology making inroads into prognosis and treatment of cancer progression and metastasis. Cancer Metastasis Rev. 39, 603-623. doi: 10.1007/s10555-02009888-5

Martins Lima, A., Martins Cavaco, A. C., Fraga-Silva, R. A., Eble, J. A., and Stergiopulos, N. (2019). From patients to platelets and back again: pharmacological approaches to glycoprotein VI, a thrilling antithrombotic target with minor bleeding risks. Thromb. Haemost. 119, 1720-1739. doi: 10.1055/s-0039- 1695770

Masucci, M. T., Minopoli, M., Del Vecchio, S., and Carriero, M. V. (2020). The emerging role of Neutrophil Extracellular Traps (NETs) in tumor progression and metastasis. Front. Immunol. 11:1749. doi: 10.3389/fimmu.2020. 01749

Mege, D., Aubert, M., Lacroix, R., Dignat-George, F., Panicot-Dubois, L., and Dubois, C. (2019). Involvement of platelets in Cancers. Semin. Thromb. Hemost. 45, 569-575. doi: 10.1055/s-0039-1693475

Menter, D. G., Kopetz, S., Hawk, E., Sood, A. K., Loree, J. M., Gresele, P., et al. (2017). Platelet "first responders" in wound response, cancer, and metastasis. Cancer Metastasis Rev. 36, 199-213. doi: 10.1007/s10555-0179682-0

Miller, L. M., Pritchard, J. M., Macdonald, S. J. F., Jamieson, C., and Watson, A. J. B. (2017). Emergence of small-molecule Non-RGD-Mimetic inhibitors for RGD integrins. J. Med. Chem. 60, 3241-3251. doi: 10.1021/acs.jmedchem. $6 \mathrm{~b} 01711$

Mittal, V. (2018). Epithelial mesenchymal transition in tumor metastasis. Annu. Rev. Pathol. 13, 395-412.

Miura, Y., Takahashi, T., Jung, S. M., and Moroi, M. (2002). Analysis of the interaction of platelet collagen receptor glycoprotein VI (GPVI) with collagen. a dimeric form of GPVI, but not the monomeric form, shows affinity to fibrous collagen. J. Biol. Chem. 277, 46197-46204. doi: 10.1074/jbc.m20402 9200 
Mohammadi, H., and Sahai, E. (2018). Mechanisms and impact of altered tumour mechanics. Nat. Cell Biol. 20, 766-774. doi: 10.1038/s41556-018-0131-2

Mongiat, M., Buraschi, S., Andreuzzi, E., Neill, T., and Iozzo, R. V. (2019). Extracellular matrix: the gatekeeper of tumor angiogenesis. Biochem. Soc. Trans. 47, 1543-1555. doi: 10.1042/bst20190653

Moser, M., Nieswandt, B., Ussar, S., Pozgajova, M., and Fassler, R. (2008). Kindlin3 is essential for integrin activation and platelet aggregation. Nat. Med. 14, 325-330. doi: $10.1038 / \mathrm{nm} 1722$

Naba, A., Clauser, K. R., Ding, H., Whittaker, C. A., Carr, S. A., and Hynes, R. O. (2016). The extracellular matrix: tools and insights for the "omics" era. Matrix Biol. 49, 10-24. doi: 10.1016/j.matbio.2015.06.003

Naba, A., Pearce, O. M. T., Del Rosario, A., Ma, D., Ding, H., Rajeeve, V., et al. (2017). Characterization of the extracellular matrix of normal and diseased tissues using proteomics. J. Proteome Res. 16, 3083-3091. doi: 10.1021/acs. jproteome.7b00191

Nagae, M., Morita-Matsumoto, K., Kato, M., Kaneko, M. K., Kato, Y., and Yamaguchi, Y. (2014). A platform of C-type lectin-like receptor CLEC-2 for binding O-glycosylated podoplanin and nonglycosylated rhodocytin. Structure 22, 1711-1721. doi: 10.1016/j.str.2014.09.009

Nagy, J. A., Dvorak, A. M., and Dvorak, H. F. (2012). Vascular hyperpermeability, angiogenesis, and stroma generation. Cold Spring Harb. Perspect. Med. 2:a006544. doi: 10.1101/cshperspect.a006544

Ngo, C. V., Picha, K., Mccabe, F., Millar, H., Tawadros, R., Tam, S. H., et al. (2007). CNTO 859, a humanized anti-tissue factor monoclonal antibody, is a potent inhibitor of breast cancer metastasis and tumor growth in xenograft models. Int. J. Cancer 120, 1261-1267. doi: 10.1002/ijc.22426

Nieswandt, B., Hafner, M., Echtenacher, B., and Mannel, D. N. (1999). Lysis of tumor cells by natural killer cells in mice is impeded by platelets. Cancer Res. 59, 1295-1300.

Nieswandt, B., Schulte, V., Bergmeier, W., Mokhtari-Nejad, R., Rackebrandt, K., Cazenave, J. P., et al. (2001). Long-term antithrombotic protection by in vivo depletion of platelet glycoprotein VI in mice. J. Exp. Med. 193, 459-469. doi: 10.1084/jem.193.4.459

Nieswandt, B., and Watson, S. P. (2003). Platelet-collagen interaction: is GPVI the central receptor? Blood 102, 449-461. doi: 10.1182/blood-2002-12-3882

Niland, S., and Eble, J. A. (2019). Neuropilins in the context of tumor vasculature. Int. J. Mol. Sci. 20:639. doi: 10.3390/ijms20030639

Niland, S., and Eble, J. A. (2020). Hold on or cut? integrin- and MMP-Mediated cell-matrix interactions in the tumor microenvironment. Int. J. Mol. Sci. 22:238. doi: $10.3390 /$ ijms 22010238

Niland, S., Westerhausen, C., Schneider, S. W., Eckes, B., Schneider, M. F., and Eble, J. A. (2011). Biofunctionalization of a generic collagenous triple helix with the alpha2betal integrin binding site allows molecular force measurements. Int. J. Biochem. Cell Biol. 43, 721-731. doi: 10.1016/j.biocel.2011. 01.013

Nuyttens, B. P., Thijs, T., Deckmyn, H., and Broos, K. (2011). Platelet adhesion to collagen. Thromb. Res. 127(Suppl. 2), S26-S29.

Ostman, A. (2017). PDGF receptors in tumor stroma: biological effects and associations with prognosis and response to treatment. Adv. Drug Deliv. Rev. 121, 117-123. doi: 10.1016/j.addr.2017.09.022

Oudin, M. J., and Weaver, V. M. (2016). Physical and chemical gradients in the tumor microenvironment regulate tumor cell invasion, migration, and metastasis. Cold. Spring Harb. Symp. Quant. Biol. 81, 189-205. doi: 10.1101/ sqb.2016.81.030817

Owens, A. P. III, and Mackman, N. (2011). Microparticles in hemostasis and thrombosis. Circ. Res. 108, 1284-1297. doi: 10.1161/circresaha.110.233056

Ozaki, Y., Suzuki-Inoue, K., and Inoue, O. (2013). Platelet receptors activated via mulitmerization: glycoprotein VI. GPIb-IX-V, and CLEC-2. J. Thromb. Haemost. 11(Suppl. 1), 330-339. doi: 10.1111/jth.12235

Pakshir, P., Noskovicova, N., Lodyga, M., Son, D. O., Schuster, R., Goodwin, A., et al. (2020). The myofibroblast at a glance. J. Cell Sci. 133:jcs227900. doi: $10.1242 /$ jcs. 227900

Palacios-Acedo, A. L., Mege, D., Crescence, L., Dignat-George, F., Dubois, C., and Panicot-Dubois, L. (2019). Platelets, thrombo-inflammation, and Cancer: collaborating with the enemy. Front. Immunol. 10:1805. doi: 10.3389/fimmu. 2019.01805

Palumbo, J. S., Talmage, K. E., Massari, J. V., La Jeunesse, C. M., Flick, M. J., Kombrinck, K. W., et al. (2007). Tumor cell-associated tissue factor and circulating hemostatic factors cooperate to increase metastatic potential through natural killer cell-dependent and-independent mechanisms. Blood 110, 133-141. doi: 10.1182/blood-2007-01-065995

Perret, S., Eble, J. A., Siljander, P. R., Merle, C., Farndale, R. W., Theisen, M., et al. (2003). Prolyl hydroxylation of collagen type I is required for efficient binding to integrin alpha 1 beta 1 and platelet glycoprotein VI but not to alpha 2 beta 1 . J. Biol. Chem. 278, 29873-29879. doi: 10.1074/jbc.m304073200

Pietras, K., and Ostman, A. (2010). Hallmarks of cancer: interactions with the tumor stroma. Exp. Cell Res. 316, 1324-1331. doi: 10.1016/j.yexcr.2010.02.045

Placke, T., Orgel, M., Schaller, M., Jung, G., Rammensee, H. G., Kopp, H. G., et al. (2012a). Platelet-derived MHC class I confers a pseudonormal phenotype to cancer cells that subverts the antitumor reactivity of natural killer immune cells. Cancer Res. 72, 440-448. doi: 10.1158/0008-5472.can-11-1872

Placke, T., Salih, H. R., and Kopp, H. G. (2012b). GITR ligand provided by thrombopoietic cells inhibits NK cell antitumor activity. J. Immunol. 189, 154-160. doi: 10.4049/jimmunol.1103194

Podolnikova, N. P., O’toole, T. E., Haas, T. A., Lam, S. C., Fox, J. E., and Ugarova, T. P. (2009). Adhesion-induced unclasping of cytoplasmic tails of integrin alpha(IIb)beta3. Biochemistry 48, 617-629. doi: 10.1021/bi801751s

Podolnikova, N. P., Yermolenko, I. S., Fuhrmann, A., Lishko, V. K., Magonov, S., Bowen, B., et al. (2010). Control of integrin alphaIIb beta3 outside-in signaling and platelet adhesion by sensing the physical properties of fibrin(ogen) substrates. Biochemistry 49, 68-77. doi: 10.1021/bi9016022

Pollitt, A. Y., Grygielska, B., Leblond, B., Desire, L., Eble, J. A., and Watson, S. P. (2010). Phosphorylation of CLEC-2 is dependent on lipid rafts, actin polymerization, secondary mediators, and Rac. Blood 115, 2938-2946. doi: 10.1182/blood-2009-12-257212

Pollitt, A. Y., Poulter, N. S., Gitz, E., Navarro-Nunez, L., Wang, Y. J., Hughes, C. E., et al. (2014). Syk and Src family kinases regulate C-type lectin receptor 2 (CLEC2)-mediated clustering of podoplanin and platelet adhesion to lymphatic endothelial cells. J. Biol. Chem. 289, 35695-35710. doi: 10.1074/jbc.m114. 584284

Poulter, N. S., Pollitt, A. Y., Owen, D. M., Gardiner, E. E., Andrews, R. K., Shimizu, H., et al. (2017). Clustering of glycoprotein VI (GPVI) dimers upon adhesion to collagen as a mechanism to regulate GPVI signaling in platelets. J. Thromb. Haemost. 15, 549-564. doi: 10.1111/jth.13613

Pugh, N., Simpson, A. M., Smethurst, P. A., De Groot, P. G., Raynal, N., and Farndale, R. W. (2010). Synergism between platelet collagen receptors defined using receptor-specific collagen-mimetic peptide substrata in flowing blood. Blood 115, 5069-5079. doi: 10.1182/blood-2010-01-260778

Quach, M. E., and Li, R. (2020). Structure-function of platelet glycoprotein Ib-IX. J. Thromb. Haemost. 18, 3131-3141. doi: 10.1111/jth.15035

Quintanilla, M., Montero-Montero, L., Renart, J., and Martin-Villar, E. (2019). Podoplanin in inflammation and Cancer. Int. J. Mol. Sci. 20:707. doi: 10.3390/ ijms20030707

Rayes, J., Lax, S., Wichaiyo, S., Watson, S. K., Di, Y., Lombard, S., et al. (2017). The podoplanin-CLEC-2 axis inhibits inflammation in sepsis. Nat. Commun. 8:2239.

Reddel, C. J., Tan, C. W., and Chen, V. M. (2019). Thrombin generation and cancer: contributors and consequences. Cancers (Basel) 11:100. doi: 10.3390/ cancers 11010100

Repetto, O., and De Re, V. (2017). Coagulation and fibrinolysis in gastric cancer. Ann. N. Y. Acad. Sci. 1404, 27-48. doi: 10.1111/nyas.13454

Rondon, A. M. R., Kroone, C., Kapteijn, M. Y., Versteeg, H. H., and Buijs, J. T. (2019). Role of tissue factor in tumor progression and Cancer-Associated Thrombosis. Semin. Thromb. Hemost. 45, 396-412. doi: 10.1055/s-00391687895

Rupp, T., Langlois, B., Koczorowska, M. M., Radwanska, A., Sun, Z., Hussenet, T., et al. (2016). Tenascin-C orchestrates glioblastoma angiogenesis by modulation of pro- and anti-angiogenic signaling. Cell Rep. 17, 2607-2619. doi: 10.1016/j. celrep.2016.11.012

Sabrkhany, S., Griffioen, A. W., and Oude Egbrink, M. G. (2011). The role of blood platelets in tumor angiogenesis. Biochim. Biophys. Acta 1815, 189-196.

Sadeghalvad, M., Mohammadi-Motlagh, H. R., and Rezaei, N. (2020). Immune microenvironment in different molecular subtypes of ductal breast carcinoma. Breast Cancer Res Treat. 185, 261-279. doi: 10.1007/s10549-020-05954-2

Sasaki, T., Shirai, T., Tsukiji, N., Otake, S., Tamura, S., Ichikawa, J., et al. (2018). Functional characterization of recombinant snake venom rhodocytin: 
rhodocytin mutant blocks CLEC-2/podoplanin-dependent platelet aggregation and lung metastasis. J. Thromb. Haemost. 16, 960-972. doi: 10.1111/jth.13987

Scharf, R. E. (2018a). Platelet signaling in primary haemostasis and arterial thrombus formation: Part 1. Hamostaseologie 38, 203-210. doi: 10.1055/s0038- 1675144

Scharf, R. E. (2018b). Platelet signaling in primary haemostasis and arterial thrombus formation: Part 2. Hamostaseologie 38, 211-222. doi: 10.1055/s0038- 1675149

Schlesinger, M. (2018). Role of platelets and platelet receptors in cancer metastasis. J. Hematol. Oncol. 11:125.

Schliemann, C., Gerwing, M., Heinzow, H., Harrach, S., Schwöppe, C., Wildgruber, M., et al. (2020). First-In-Class CD13-Targeted tissue factor tTF-NGR in patients with recurrent or refractory malignant tumors: results of a phase I dose-escalation study. Cancers (Basel) 12, 1488. doi: 10.3390/cancers12061488

Schwöppe, C., Kessler, T., Persigehl, T., Liersch, R., Hintelmann, H., Dreischaluck, J., et al. (2010). Tissue-factor fusion proteins induce occlusion of tumor vessels. Thromb. Res. 125(Suppl. 2), S143-S150.

Severin, S., Pollitt, A. Y., Navarro-Nunez, L., Nash, C. A., Mourao-Sa, D., Eble, J. A., et al. (2011). Syk-dependent phosphorylation of CLEC-2: a novel mechanism of hem-immunoreceptor tyrosine-based activation motif signaling. J. Biol. Chem. 286, 4107-4116.

Shoji, M., Hancock, W. W., Abe, K., Micko, C., Casper, K. A., Baine, R. M., et al. (1998). Activation of coagulation and angiogenesis in cancer: immunohistochemical localization in situ of clotting proteins and vascular endothelial growth factor in human cancer. Am. J. Pathol. 152, 399-411.

Simons, K., and Gerl, M. J. (2010). Revitalizing membrane rafts: new tools and insights. Nat. Rev. Mol. Cell Biol. 11, 688-699.

Spalton, J. C., Mori, J., Pollitt, A. Y., Hughes, C. E., Eble, J. A., and Watson, S. P. (2009). The novel Syk inhibitor R406 reveals mechanistic differences in the initiation of GPVI and CLEC-2 signaling in platelets. J. Thromb. Haemost. 7, 1192-1199.

Springer, T. A., Zhu, J., and Xiao, T. (2008). Structural basis for distinctive recognition of fibrinogen gammaC peptide by the platelet integrin alphaIIbbeta3. J. Cell Biol. 182, 791-800.

Stone, M. J., Ruf, W., Miles, D. J., Edgington, T. S., and Wright, P. E. (1995). Recombinant soluble human tissue factor secreted by Saccharomyces cerevisiae and refolded from Escherichia coli inclusion bodies: glycosylation of mutants, activity and physical characterization. Biochem. J. 310(Pt 2), 605-614.

Suzuki-Inoue, K. (2019). Platelets and cancer-associated thrombosis: focusing on the platelet activation receptor CLEC-2 and podoplanin. Blood 134, 1912-1918.

Suzuki-Inoue, K., Fuller, G. L., Garcia, A., Eble, J. A., Pohlmann, S., Inoue, O., et al. (2006). A novel Syk-dependent mechanism of platelet activation by the C-type lectin receptor CLEC-2. Blood 107, 542-549.

Swier, N., and Versteeg, H. H. (2017). Reciprocal links between venous thromboembolism, coagulation factors and ovarian cancer progression. Thromb. Res. 150, 8-18.

Swieringa, F., Spronk, H. M. H., Heemskerk, J. W. M., and Van Der Meijden, P. E. J. (2018). Integrating platelet and coagulation activation in fibrin clot formation. Res. Pract. Thromb. Haemost. 2, 450-460.

Tesselaar, M. E., Romijn, F. P., Van Der Linden, I. K., Bertina, R. M., and Osanto, S. (2009). Microparticle-associated tissue factor activity in cancer patients with and without thrombosis. J. Thromb. Haemost. 7, 1421-1423.

Theocharis, A. D., Skandalis, S. S., Gialeli, C., and Karamanos, N. K. (2016). Extracellular matrix structure. Adv. Drug Deliv. Rev. 97, 4-27.

Trousseau, A. (1865). Plegmasia alba dolens. Lectures Clin. Med. 5, 281-332.

Tsukiji, N., Osada, M., Sasaki, T., Shirai, T., Satoh, K., Inoue, O., et al. (2018). Cobalt hematoporphyrin inhibits CLEC-2-podoplanin interaction, tumor metastasis, and arterial/venous thrombosis in mice. Blood Adv. 2, 2214-2225.

Unruh, D., and Horbinski, C. (2020). Beyond thrombosis: the impact of tissue factor signaling in cancer. J. Hematol. Oncol. 13:93.

Vajen, T., Mause, S. F., and Koenen, R. R. (2015). Microvesicles from platelets: novel drivers of vascular inflammation. Thromb. Haemost. 114, 228-236.

van den Berg, Y. W., Osanto, S., Reitsma, P. H., and Versteeg, H. H. (2012). The relationship between tissue factor and cancer progression: insights from bench and bedside. Blood 119, 924-932. van Golen, R. F., Stevens, K. M., Colarusso, P., Jaeschke, H., and Heger, M. (2015). Platelet aggregation but not activation and degranulation during the acute postischemic reperfusion phase in livers with no underlying disease. J. Clin. Transl. Res. 1, 107-115.

Versteeg, H. H. (2015). Tissue factor: old and new links with Cancer biology. Semin. Thromb. Hemost. 41, 747-755.

Versteeg, H. H., Schaffner, F., Kerver, M., Petersen, H. H., Ahamed, J., FeldingHabermann, B., et al. (2008). Inhibition of tissue factor signaling suppresses tumor growth. Blood 111, 190-199.

Vickers, J. D. (1998). In contrast to fibrinogen or fibrin, peptide and peptide mimetic binding to alphaIIbbeta3 (GPIIb-IIIa) does not cause outside-in signalling as judged by measurements of phosphatidylinositol 4,5-bisphosphate. Platelets 9, 390-394.

Wang, M., Zhao, J., Zhang, L., Wei, F., Lian, Y., Wu, Y., et al. (2017). Role of tumor microenvironment in tumorigenesis. J. Cancer 8, 761-773.

Wang, X., Liu, B., Xu, M., Jiang, Y., Zhou, J., Yang, J., et al. (2021). Blocking podoplanin inhibits platelet activation and decreases cancer-associated venous thrombosis. Thromb. Res. 200, 72-80.

Wang, Y., Gallant, R. C., and Ni, H. (2016). Extracellular matrix proteins in the regulation of thrombus formation. Curr. Opin. Hematol. 23, 280-287.

Ward, Y., Lake, R., Faraji, F., Sperger, J., Martin, P., Gilliard, C., et al. (2018). Platelets promote metastasis via binding tumor CD97 leading to bidirectional signaling that coordinates transendothelial migration. Cell Rep. 23, 808-822.

Watson, A. A., Christou, C. M., James, J. R., Fenton-May, A. E., Moncayo, G. E., Mistry, A. R., et al. (2009). The platelet receptor CLEC-2 is active as a dimer. Biochemistry 48, 10988-10996.

Watson, A. A., Eble, J. A., and O'callaghan, C. A. (2008). Crystal structure of rhodocytin, a ligand for the platelet-activating receptor CLEC-2. Protein Sci. 17, 1611-1616.

Wculek, S. K., and Malanchi, I. (2015). Neutrophils support lung colonization of metastasis-initiating breast cancer cells. Nature 528, 413-417.

Wechman, S. L., Emdad, L., Sarkar, D., Das, S. K., and Fisher, P. B. (2020). Vascular mimicry: triggers, molecular interactions and in vivo models. Adv. Cancer Res. $148,27-67$.

Wei, J., Hu, M., Huang, K., Lin, S., and Du, H. (2020). Roles of proteoglycans and glycosaminoglycans in Cancer development and progression. Int. J. Mol. Sci. 21:5983.

Wei, X., Chen, Y., Jiang, X., Peng, M., Liu, Y., Mo, Y., et al. (2021). Mechanisms of vasculogenic mimicry in hypoxic tumor microenvironments. Mol. Cancer 20:7.

White, J. G. (2000). EDTA-induced changes in platelet structure and function: clot retraction. Platelets 11, 49-55.

Wojtukiewicz, M. Z., Hempel, D., Sierko, E., Tucker, S. C., and Honn, K. V. (2015). Protease-activated receptors (PARs)-biology and role in cancer invasion and metastasis. Cancer Metastasis Rev. 34, 775-796.

Wojtukiewicz, M. Z., Hempel, D., Sierko, E., Tucker, S. C., and Honn, K. V. (2016). Thrombin-unique coagulation system protein with multifaceted impacts on cancer and metastasis. Cancer Metastasis Rev. 35, 213-233.

Wolf, M. J., Hoos, A., Bauer, J., Boettcher, S., Knust, M., Weber, A., et al. (2012). Endothelial CCR2 signaling induced by colon carcinoma cells enables extravasation via the JAK2-Stat5 and P38MAPK pathway. Cancer Cell 22, 91-105.

Wong, A. K. (2013). Platelet biology: the role of shear. Expert Rev. Hematol. 6, 205-212.

Wu, L., Saxena, S., Awaji, M., and Singh, R. K. (2019). Tumor-Associated neutrophils in Cancer: going pro. Cancers (Basel) 11:564.

Xiao, T., Takagi, J., Coller, B. S., Wang, J. H., and Springer, T. A. (2004). Structural basis for allostery in integrins and binding to fibrinogen-mimetic therapeutics. Nature 432, 59-67.

Xiong, F., Hausdorf, J., Niethammer, T. R., Jansson, V. A., and Klar, R. M. (2020). Temporal TGF-beta supergene family signalling cues modulating tissue morphogenesis: chondrogenesis within a muscle tissue model? Int. J. Mol. Sci. 21:4863.

Xiong, G., Chen, J., Zhang, G., Wang, S., Kawasaki, K., Zhu, J., et al. (2020). Hsp47 promotes cancer metastasis by enhancing collagen-dependent cancer cell-platelet interaction. Proc. Natl. Acad. Sci. U S A. 117, 3748-3758.

Yang, Y., Yang, Y., Yang, J., Zhao, X., and Wei, X. (2020). Tumor microenvironment in ovarian cancer: function and therapeutic strategy. Front. Cell Dev. Biol. 8:758. doi: $10.3389 /$ fcell. 2020.00758 
Yeung, J., Li, W., and Holinstat, M. (2018). Platelet signaling and disease: targeted therapy for thrombosis and other related diseases. Pharmacol. Rev. 70, 526-548.

Zanotelli, M. R., and Reinhart-King, C. A. (2018). Mechanical forces in tumor angiogenesis. Adv. Exp. Med. Biol. 1092, 91-112.

Zhang, B., Pang, Z., and Hu, Y. (2020). Targeting hemostasis-related moieties for tumor treatment. Thromb. Res. 187, 186-196.

Zheng, Y., and Leftheris, K. (2020). Insights into protein-ligand interactions in integrin complexes: advances in structure determinations. J. Med. Chem. 63, 5675-5696.
Conflict of Interest: The authors declare that the research was conducted in the absence of any commercial or financial relationships that could be construed as a potential conflict of interest.

Copyright (C) 2021 Obermann, Brockhaus and Eble. This is an open-access article distributed under the terms of the Creative Commons Attribution License (CC BY). The use, distribution or reproduction in other forums is permitted, provided the original author(s) and the copyright owner(s) are credited and that the original publication in this journal is cited, in accordance with accepted academic practice. No use, distribution or reproduction is permitted which does not comply with these terms. 